Ulf Norling*

\title{
Growth, winter preparations and timing of emergence in temperate zone Odonata : control by a succession of larval response patterns
}

https://doi.org/10.23797/2159-6719_24_1

Review article

Received 27 March 2020; Accepted 11 August 2020; Published 04 March 2021

\begin{abstract}
As warm-adapted insects of tropical origin, Odonata cope with cold periods by seasonal regulation and diapause. A model for larval-overwintering species is proposed with three response patterns related to the timing of emergence, which can be predicted from seasonal cues during the last few stadia. For emergence during the present season, there is an often time constrained preemergence development, accelerated by long days and higher temperatures. In regulatory development, emergence is postponed to the next season, and a complex of diapause-like delays controlled by photoperiod and temperature prevents premature emergence. Instead, development converges on a winter diapause in sizes suitable for emergence during the following year. Long days are particularly delaying, and thermal responses are variable, sometimes inverted. In early development, with rapid growth, emergence is usually not predicted to season, but short-day winter diapauses may occur, and precocious preparations for a penultimate winter may be predictive. Thermal responses are steep, extremely so if a short-day diapause is suppressed by higher temperatures. Other physiological and also behavioural properties may differ between response patterns. Changes in photoperiod and temperature control the timing of seasonal events, and the transition from regulatory to pre-emergence development follows the increase in temperature and photoperiod after winter, which is an important time-setter. Interactions of larval size, photoperiod, temperature and previous changes affect development rate, and long-term constant conditions often end in regulatory diapauses. Proximate mechanisms of cohort splitting and the implications of the model for design and interpretation of experiments are discussed.
\end{abstract}

Keywords: life history; seasonal regulation; cohort splitting; diapause; quiescence; photoperiod; thermal responses; time constraint; phenology; dragonfly

\section{Introduction}

Odonata are tropical-centred insects and require comparatively high temperatures for development and activity and have adapted to colder climates via diapause phenomena in seasonal regulation (Box 1), whereas many other aquatic exopterygotes have done so by adapting their temperature responses (Pritchard, 1982; Pritchard, Harder \& Mutch, 1996). Seasonal regulation includes the appropriate seasonal adjustment of development to limit emergence to a temporal window that allows a successful reproduction, and that a resistant stage can be reached before winter. This overwintering stage, often in diapause, can be egg, larva, or more rarely, the adult (Corbet, 1999). The last winter should also be spent in a stage suitable as a starting point for development to the next season's emergence.

Box 1. Seasonal regulation and diapause

Seasonal regulation is an "array of responses whereby each developmental stage tends to be confined to a particular season" (Corbet, 1999, p. 586). The responses often take the shape of a diapause, which is a hormonally controlled arrest or delay in development in preparation for adverse conditions. This concept is used in a wide sense in the present account. See also Box 8.

The present account is restricted to temperate zone species with flexible voltinism and seasonal regulation in the larval stage, where at least the last winter is spent. The main subject is how patterns of 
responses to environmental cues such as photoperiod and temperature during different times and stages of larval development can proximately explain the timing of emergence and winter preparations, and so phenology and adaptations to different latitudes and climates (cf. Corbet, 1999; Norling, 1984c). It also explores the sometimes neglected importance of changes, including winter as a timesetter, and the effects of seasonal regulation responses on thermal reaction norms and most likely on behaviour.

Life histories of these temperate species can range from very asynchronous development and emergence, with full or partial multi- and bivoltinism (Figure 1a), via intermediate uni- to semivoltine development (b-d) to early synchronous emergence (e, f), and/or multi-year development (f-h). Sometimes there is an additional obligatory or facultative egg diapause $(\mathrm{g}, \mathrm{h})$, enabling late reproduction (Corbet, 1999, p. 56).

Philip Corbet pioneered the study of dragonfly seasonal regulation, presenting stimulating and provocative ideas in a series of publications from 1954 and onwards (Corbet, 1954, 1955, 1956b, 1957a-c; Corbet \& Corbet, 1958), later summed up in two early books (Corbet, 1960; Corbet, 1962). These ideas were centred on the concepts of spring and summer species, which were assumed to be fundamentally different (Box 2). The spring species pattern was caused by a diapause in the last larval stadium (F-0; Box 3), whereas summer species were supposed to lack a larval diapause, at least in F-0.

\section{Box 2. Spring and summer species}

Spring species is a population with an early and well synchronized emergence, spending the winter before emergence at least mainly in the final larval stadium (Figure 1e, f). It is no longer regarded as a property on the species level.

Summer species is a population with a dispersed, asynchronous emergence, not spending the winter before emergence mainly in the final stadium but either in several stadia (Figure 1a-d, g, h), or, as in the original definition, also as eggs or even adults (Corbet, 1956a).

\section{Box 3. Larval stadia in Odonata}

Stadium means the period between two ecdyses. Although instar is often used in this sense, instar can also mean the period between two apolyses (cf. Box 9). Stadia are usually counted backwards from the final one (F-0; final minus zero, F-1 etc.) because of the unstable total number, which can range between 8 and 18 in Odonata, including the prolarva. See also Corbet (2002).

These ideas stimulated research in the field, and it later transpired that spring species and those summer species overwintering as larvae, i. e. the categories treated in this paper, formed a continuum in seasonal regulation, and that also conspecific populations could be different (Paulson \& Jenner, 1971). Based on later research, Corbet (1999, p. 220) presented a review of seasonal regulation and a comprehensive classification of life histories, where these species are characterised as "regulated: voltinism facultative" (type 2.2; cf. also Suhling, Sahlén, et al., 2015, p. 916-917). However, spring and summer species are still useful concepts as a shorthand for patterns of development and phenology, but they are not properties at the species level (Corbet, 2003).

A crucial component in the basic framework of seasonal regulation during larval development, at least in colder temperate areas, can be summarized as a temperature-assisted two-step photoperiodic reaction, as described below. The present paper provides an update and expansion of this model, although some details may be more completely described in the original publication, which also had a different approach (Norling, 1984c). This update is primarily dealing with proximate responses to seasonal cues and is based on old and new data of variable quality, including field studies and some intuitive reasoning, and is so partly well documented and partly speculative and hypothetical. 

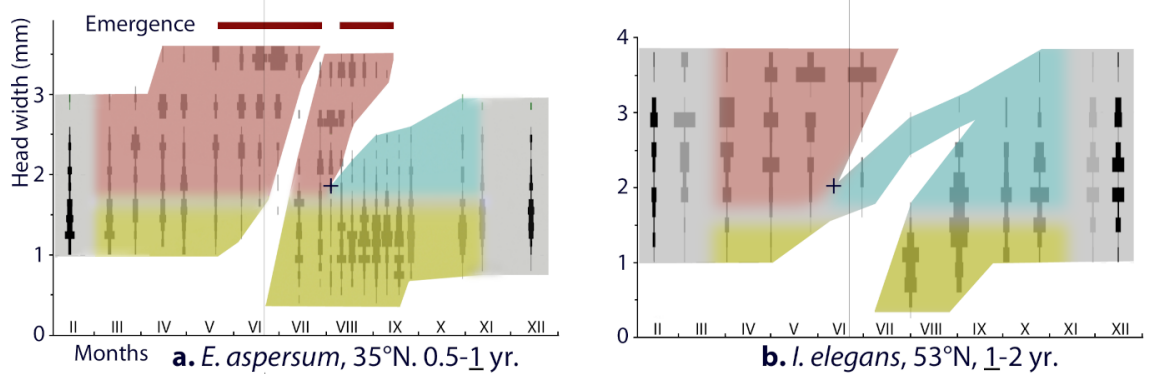

Fast, asyn-

chronous

"summer

species";

known

capacity for

bivoltinism
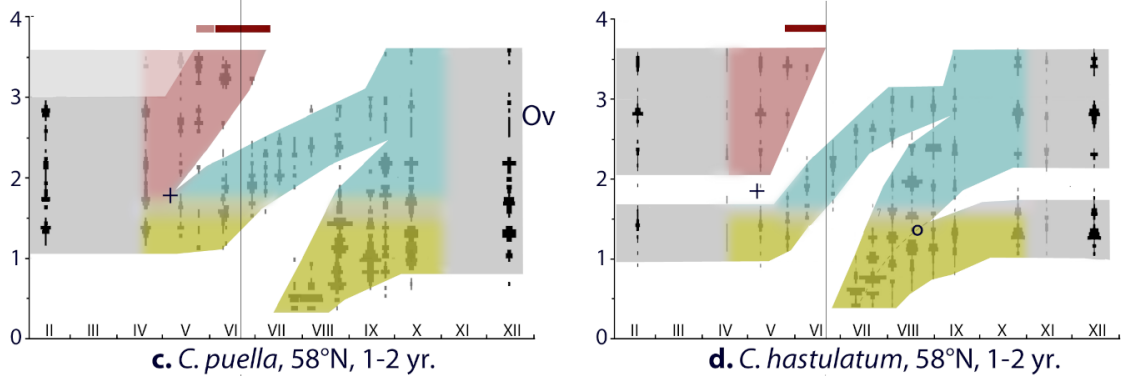

Fast, tran-

sition to

early, more

synchronous

"summer

species"

d. C. hastulatum, $58^{\circ} \mathrm{N}, 1-2 \mathrm{yr}$.
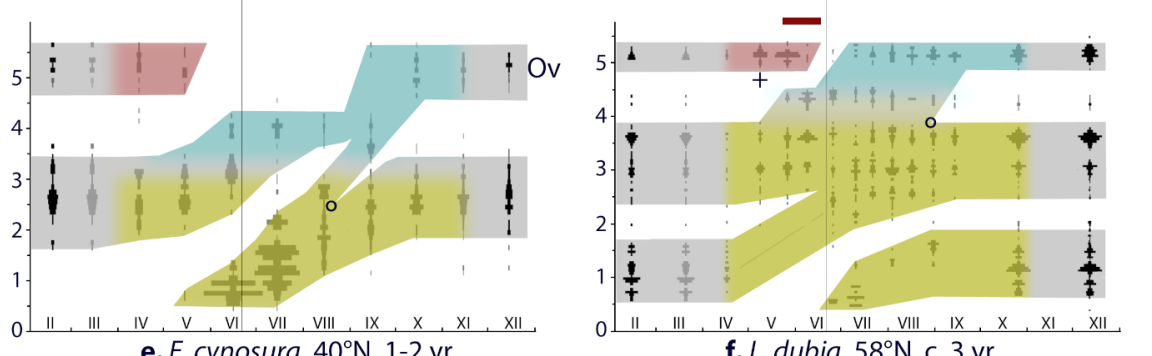

Fast and

slow

"spring

species"

e. E. cynosura, $40^{\circ} \mathrm{N}, 1-\underline{2} \mathrm{yr}$.
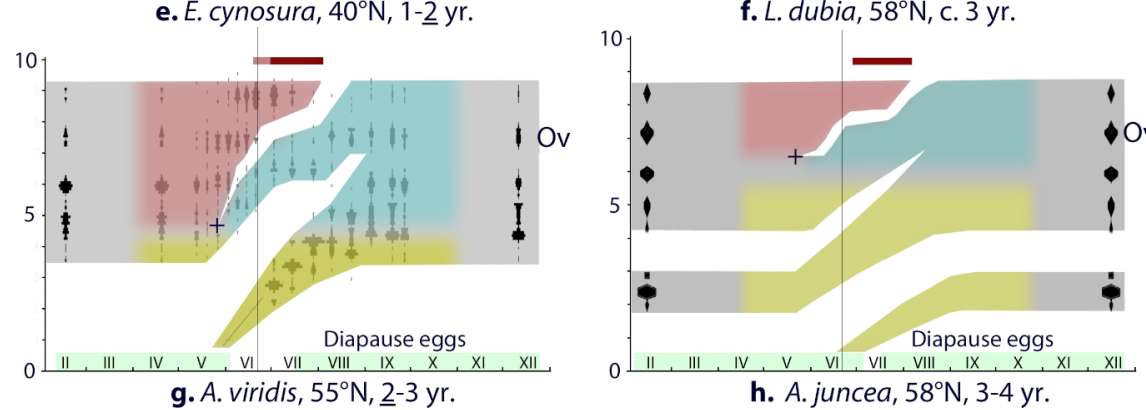

Slow,

asynchro-

nous late

"summer

species"

with

diapause

eggs

Figure 1. Life history graphs of eight species, with the later discussed response patterns estimated as colour-coding (see Table 1) and arranged after phenology and duration. Underlying kite diagrams are shown except in (h). The emergence period is indicated when known from either exuvial collections (a) or estimated from observations of F-0 intrastadium development (the rest; see Norling, 1971, 1976, 1984a). In $(c)$ and $(g)$ emergence from rare overwintering F-0 is shown with lighter shade. The summer solstice is indicated with thin vertical lines as a summertime reference. Legend: grey: winter stasis or uncertain; yellow: early development; blue : regulatory development; red : pre-emergence development; "Ov": overlap after cohort merging; o pre-hibernation cohort split; + emergence cohort split.

Sources and locations: (a) Enallagma aspersum, assembled from data in Ingram \& Jenner (1976b). North Carolina, U. S. A., 1968 - 69. (b) Ischnura elegans, drawn from data in Parr (1970). England, 1968. (c) Coenagrion puella, part of a survey 2011 - 2019. Sweden, 2011 - 2012 superimposed. (d) Coenagrion hastulatum, modified from Norling (1984a). Sweden, same place as (f), 1973. (e) Epitheca cynosura, drawn from data in Johnson (1986). Tennessee, U. S. A., 1977-1985 combined. (f) Leucorrhinia dubia, cf. Norling (1976, 1984b, c). Sweden, same place as (d), 1973. (g) Aeshna viridis, cf. Norling (1971, 1984c). Sweden, 1970. (h) Aeshna juncea, modified from figure 6b in Norling (1984c). Part of a survey 1965-1973. Sweden, one year-class 1967-1970. 


\section{Cohort splitting and the two-step "winter critical size (WCS) model"}

Species overwintering as larvae normally change voltinism with the conditions for development (Corbet, Suhling \& Soendgerath, 2006), and often display cohort splits (Box 4), which often expose key responses in seasonal regulation. A cohort split can be initiated during different parts of the life cycle (Figure 1), and different names are here proposed for these splits (Box 5).

\section{Box 4. The often overlooked cohort splits in Odonata}

In a cohort split, individuals of the same age go for emergence in different years. Although well known in Odonata, it is probably underreported due to poor quality of data, information loss in presentations with fixed instar groups or with other lumping and data-smoothing methods. When age cohorts are overlapping, even good data may conceal cohort splits (Figure 1f; cf. figure 15 and 17 in Deacon, 1979). Small, often unlikely fast cohorts are easily overlooked, but can give an important contribution to the emerging population due to higher overall survival (Johnson, 1986; cf. Figure 1e). In a split after a previous merging, fast larvae may often change cohort undetected, which is almost the case for three-year development in Figure $1 \mathrm{~h}$.

\section{Box 5. Types of cohort splitting in Odonata}

An emergence cohort split is initiated during the season of emergence of the fast cohort, so separating one emerging and one overwintering cohort, shown as + in Figure 1. A pre-hibernation cohort split separates two cohorts which both overwinter, and only the fast cohort emerges next season (Figure 1d-f, shown as $\bigcirc$ ). Acts as a precursor to an emergence split, which is best illustrated in Figure 1d.

Crowley \& Hopper (2015) explored ultimate mechanisms for cohort splitting in a mathematical model showing that random variation in development rate is a main general feature driving cohort splits. However, the different ultimate mechanisms dealt with by Crowley \& Hopper (2015) are normally not addressed in the present account, and the "midpoint cueing" mechanism is assumed to apply. Here a split is initiated from perceived cues during larval development, which seems to fit at least the emergence split. It starts at a critical size or stage at a critical time (Ingram, 1971, p. $114-$ 116; Norling, 1984c) (Box 6) and the mechanism may be favoured by constraints and uncertainties in connecting ultimate factors to proximate cues and responses.

\section{Box 6. Thresholds for initiation of a cohort split}

Critical time is the time of the season when a cohort split is initiated, and the critical size (or stage) is the size (stage) where the split appears. When the critical size is reached before the critical time, a larva enters the fast cohort in a split; if later, the larva enters the slow cohort. The critical size can also be described as a critical stadium, but in smaller sizes stadium assignation can be complicated by extra moults in the slow cohort (e. g. Corbet, 2002; Norling, 1984a).

After both field and experimental studies of cohort splitting in Odonata from different parts of Sweden, I proposed the two-step "winter critical size (WCS) model" for an emergence cohort split, mainly assumed to apply at higher latitudes. Here the split took place in spring directly after winter at a "winter critical size" (Box 7; Norling, 1984c; also described in Corbet, 1999, p.230, and 2003; see also Furunishi \& Masaki, 1983 and Zaslavsky, 1972, for two-step reactions).

\section{Box 7. WCS or winter critical size.}

This is a special case in the control of an emergence cohort split where the critical time is immediately after winter, and the critical size (or stage) is realized in the overwintering population. Only larvae overwintering above the WCS will enter fast development in spring and emerge. Typical for early-flying species and at higher latitudes. 
The split separated two essentially opposite responses to photoperiod (the "discrete strategies" in Corbet, 2003). It was observed that if overwintering larvae were experimentally exposed to summer photoperiods and temperatures, those larvae overwintering above a particular size (the WCS) were accelerated to emergence, whereas smaller larvae instead grew slowly from the beginning, eventually entering stronger long-day diapauses, often during several late stadia. In the field, the latter larvae postponed emergence to the following season, and ultimately encountered winter in a short-day maintained diapause.

Development to emergence only occurred if larvae above the WCS were taken from short photoperiods (autumn, winter or early spring, or short days in the lab) to long days. So, whenever larvae reached the approximate size of the WCS later than spring, they started the above-mentioned longterm preparation for winter, which is the first step in the two-step mechanism. The second step is the subsequent long-day accelerated development after the spring transition above the WCS.

In these experiments, the WCS was plastic and dependent on photoperiod-temperature combinations during spring, which indicate the likely potential to successfully complete development and reproduce during the remaining season (time stress). The experimentally observed responses, including plasticity, were corroborated by field observations (see also Box 12).

The WCS differed between species and also between populations (see Norling, 1984c and references in Figure 1). The spring species Leucorrhinia dubia (Vander Linden) only emerged after a winter in F-0 (Figure 1f), whereas the summer species Aeshna viridis Eversmann could overwinter in the last four stadia and still emerge (Figure 1g). South Swedish populations of Coenagrion hastulatum (Charpentier) and Aeshna juncea (Linnaeus), were mainly behaving as summer species (Figure $1 \mathrm{~d}, \mathrm{~h})$, but in northernmost Sweden where summers are short these two species were genetically restricted to a spring species pattern.

This two-step WCS model did not explain emergence cohort splits starting later in the season, i.e. at a later critical time. In a detailed documentation of the emergence (bivoltine) cohort split in Enallagma aspersum (Hagen) (Figure 1a), Ingram (1971, p. 116) and Ingram \& Jenner (1976b) demonstrated that larvae reaching one of the 3 or 4 last stadia (critical size) before early August (critical time), developed rapidly to emergence. Larvae reaching this size later developed slowly and prepared for a winter spent in F-1 or earlier. The proximate factors behind the split were never understood. It seemed that the WCS model was just a simple high-latitude case of an unknown, more general mechanism (cf. Norling, 1984c, p. 151). Recent data on Lestes sponsa (Hansemann) suggest that decreasing summer photoperiods might amplify a time constraint response otherwise typical for long days (Norling, 2018). Thus, there may be a seasonal gradient of increasing time constraint, first by a step from short to medium-long days in spring, then by longer days during summer, and later by a decrease from solstice photoperiods. Different species and populations can be hypothesized to sense and utilize this gradient differently in order to split at a suitable time and size, so extending the WCS model.

\section{A hypothesis of successive response patterns and prediction of emergence}

With the extended WCS model as a fundament, larval development in the temperate zone can be subdivided into three modes or programs of development, displaying different response patterns to environmental cues such as photoperiod and temperature. These response patterns are focused on prediction of emergence and have different seasonal outcomes. They are here referred to with separate, yet tentative names, and are summarized in Table 1, which also anticipates some of the later discussions. Their likely occurrence and relationships are also indicated in the life cycles in Figure 1, and diagrammatically in Figure 2. 
Table 1. Summary of properties of the different larval response patterns (modes of development), seen in seasonal regulation of temperate zone dragonflies. Colour coding provides cross-reference to Figures 1, 2 and 7 . Note that the content is partly anticipating later sections.

\begin{tabular}{|c|c|c|c|c|}
\hline $\begin{array}{l}\text { Response } \\
\text { pattern } \\
\text { (mode) }\end{array}$ & $\begin{array}{l}\text { Sizes } \\
\text { affected }\end{array}$ & General features & $\begin{array}{l}\text { Responses to } \\
\text { photoperiod }\end{array}$ & $\begin{array}{l}\text { Likely responses } \\
\text { to temperature }\end{array}$ \\
\hline $\begin{array}{l}\text { Pre-emer- } \\
\text { gence devel- } \\
\text { opment }\end{array}$ & $\begin{array}{l}\text { Late stadia, } \\
\text { often the last } \\
4 \text { (predictive } \\
\text { size range) }\end{array}$ & $\begin{array}{l}\text { Emergence predicted } \\
\text { for the present season. } \\
\text { Fast development to } \\
\text { emergence. } \\
\text { Predominantly early sea- } \\
\text { son. }\end{array}$ & $\begin{array}{l}\text { Long days are ac- } \\
\text { celerating. } \\
\text { In bivoltines a de- } \\
\text { crease might accel- } \\
\text { erate (Fig. 1a). }\end{array}$ & Steep \\
\hline $\begin{array}{l}\text { Regulatory } \\
\text { (last-winter) } \\
\text { development }\end{array}$ & $\begin{array}{l}\text { Late stadia, } \\
\text { often the last } \\
4 \text { (predictive } \\
\text { size range) }\end{array}$ & $\begin{array}{l}\text { Emergence predicted } \\
\text { for next season. } \\
\text { Slow development to } \\
\text { delay emergence, some- } \\
\text { times faster, converging } \\
\text { on a stage suitable as a } \\
\text { starting point for next } \\
\text { year (cf. Fig. 1b-e, g). } \\
\text { Mostly late season. }\end{array}$ & $\begin{array}{l}\text { In long days a } \\
\text { strong diapause } \\
\text { component. } \\
\text { In shorter days a } \\
\text { temporary fast de- } \\
\text { velopment in smal- } \\
\text { ler predictive sizes. } \\
\text { Ends in diapause at } \\
\text { all photoperiods. } \\
\text { Reset to pre-em. af- } \\
\text { ter winter. }\end{array}$ & $\begin{array}{l}\text { Variable. } \\
\text { May be flat or } \\
\text { even inverse (an } \\
\text { aestivation dia- } \\
\text { pause characteris- } \\
\text { tic). }\end{array}$ \\
\hline $\begin{array}{l}\text { Early } \\
\text { development }\end{array}$ & $\begin{array}{l}\text { Smaller } \\
\text { larvae }\end{array}$ & $\begin{array}{l}\text { No responses predicting } \\
\text { emergence (?) } \\
\text { Typically, fast growth. } \\
\text { Winter preparation when } \\
\text { needed. } \\
\text { All season. }\end{array}$ & $\begin{array}{l}\text { Usually none. } \\
\text { A short-day induced } \\
\text { winter diapause in } \\
\text { some northern spe- } \\
\text { cies (cf. Fig. 1f, h). }\end{array}$ & $\begin{array}{l}\text { Steep. } \\
\text { A winter diapause } \\
\text { may further in- } \\
\text { crease steepness. }\end{array}$ \\
\hline
\end{tabular}

\section{Mode 1. Early development}

Development in smaller sizes, where emergence is not supposed to be well predicted, is simply referred to as early development. Such larvae are provisionally assumed to develop at an optimum rate for growth and survival during summer conditions, and to be largely driven by food and temperature; however, a dedicated winter diapause may occur. This is the most uncertain and least supported response pattern, probably heterogeneous and even partly predictive.

\section{Mode 2. Regulatory development: preparation for the last winter}

In the development of the slow cohort in an emergence split, larvae appear to sense that emergence and reproduction are not feasible within the season, and must be postponed to the next summer. An excessive time constraint necessitates adding one extra year to development, transforming into a time surplus. Development is instead preventing emergence and is preparatory for the last winter - the first step in the two-step response. The name regulatory development is used for this usually slow development, although regulatory responses in a wider sense are also otherwise present during development, e.g. acceleration in pre-emergence development and dedicated winter diapauses in smaller larvae. 


\section{Mode 3. Pre-emergence development: preparation for reproduction}

In this most straightforward mode, larvae are assumed to sense that emergence and reproduction are within reach during the present season. They develop fast to emergence, as seen in the often time constrained and accelerated cohort in an emergence cohort split - the second step in the two-step response.

\section{A hypothetical predictive size range}

The last two modes or response patterns ( 2 and 3 ) are hypothesized to occur as alternative or successive programs of development within an approximate predictive size range, often about the four last stadia, in which the season and timing of emergence can be reasonably predicted from environmental cues. As discussed later, there are indications that prediction of emergence may sometimes extend below the critical size of the emergence cohort split.

\section{Uncertainty and timing of prediction}

An early determination of development rates in a cohort split and so response patterns should be an advantage if prediction is accurate enough. Accelerated high rates are costly: predation during increased foraging, often smaller, less fit adults from time stress (Stoks, Johansson \& De Block, 2008) and direct physiological costs leading to increased mortality (Dmitriew, 2011; Stoks, Swillen \& De Block, 2012; Suhling, Suhling \& Richter, 2015). This is traded off against the costs of an extra year in development: increased total mortality due to longer time in the larval stage, and fitness loss by prolongation of development (Roff, 1983). With an early prediction these alternative costs can be optimized. The reliability of cues and so prediction is likely to improve with size and time (Danks, 1987, p. 80; Roff, 1983). The lower end of the predictive range, as seen in the interface between early and regulatory or pre-emergence development, is probably indistinct and plastic, and dependent on the strength and reliability of the predictive cues. Uncertainties in prediction such as variation in conditions for development (e.g. temperature, food) favour a later decision, which reduces the predictive range (cf. Crowley \& Hopper, 2015). The transition to the predictive range may be an extended interval when size/stage, present and past cues (photoperiod, temperature), physiological state, perhaps food, competition and presence of predators are integrated. In this hypothesized plastic interface, with a long period of sensitivity to cues, larvae can continuously adjust development to new information (cf. a similar discussion by Danks, 1987, p. 80, in a slightly different context).

\section{Diapause phenomena and rates of larval development}

\section{What is diapause?}

Diapause is not always easily defined and is in its widest sense a central component in most responses in odonate seasonal regulation (Corbet, 1999), and its functions and interactions are pivotal in the later discussions. In many insects, in particular endopterygotes, there is a specific developmental stage, where a well-defined diapause can take place or not in an all-or-none fashion, and diapause is also often induced at a well-defined preceding stage (e.g. Denlinger, Yocum, \& Rinehart, 2012). However, in Odonata, and in many other insects, often exopterygotes (Danks 1987, p. 66-69, 2002), diapause can be induced in many larval stadia, even repeatedly, and with varying intensities and a continuous sensitivity to inductive cues (Corbet, 1999, p. 234; Danks, 1987, p. 225 -6; Norling 1984c). In fact, responses affecting development rate in dragonfly larvae can range continuously from a costly time constrained acceleration of development (Dmitriew, 2011; Stoks, et al., 2008) via routine development (a somewhat indistinct non-stressed development; De Block, Slos, Johansson \& 
Stoks, 2008) and low-intensity diapause-like states all the way to an intense diapause standstill (e.g. Norling, 1971, in Aeshna; Norling, 1984a and Sawchyn, 1971, in Coenagrion). To define the stages in this successive transition is of course arbitrary. Three fundamental concepts relevant in this connection are outlined in Box 8.

\section{Box 8. Concepts related to diapause}

Dormancy can be defined as all kinds of adaptive suppressed development associated with various adverse conditions (e.g. Danks, 1987, p. 7-9; Koštál, 2006), in the present context always a temperate zone winter. Within the dormancy category, we can define a range of subcategories in different ways (e.g. Mansingh, 1971; H. J. Müller, 1970, 1992), but in particular the treatise of H. J. Müller (1992) highlights the connectedness of different subcategories. Therefore, a simple, more common subdivision with two categories is used here:

Quiescence is a simple and immediate response to an unanticipated and directly limiting adversity, e. g. low temperatures, and ends with the end of the adversity. Survival of the adversity is an evolved adaptive feature also in quiescence (Koštál, 2006; Tauber et al., 1986, p. 24; cf. also H. J. Müller, 1992, p. $20-22$ ), and is perhaps prepared via acclimation. The adaptation appears to be simple, but it probably merges seamlessly with other forms of dormancy, here referred to as diapause (H. J. Müller, 1992; Norling, 1984c, p. 130).

Diapause is a hormonally controlled resting condition or suppression of development, preparing for and preceding the onset of adverse conditions, and it may continue after the end of adversity (e. g. Koštál, 2006). In larvae it is seen as a postponement of apolysis. It is usually induced by other environmental predictive cues, most often photoperiod, and its termination may be complex. Diapause is diverse and is in this paper often used in a wide and even extended sense, mainly for lack of a better alternative: any intensity of delay of development preceding an adversity.

The extended concept of diapause used here can be motivated by function (Tauber et al., 1986, p. 41), and the mentioned lack of distinction from non-diapause development of different rates seen in the same stages as more typical diapauses. Also, larval diapause mainly works through the same kind of hormonal control as the moult-intermoult cycle in normal development (Box 9; Denlinger et al., 2012; Schaller, Andries, Mouze \& Defossez, 1974). Thus, diapause as used here includes reduced development rate with a corresponding hormonally controlled but weaker delay. Larval development can be seen as a composite of an active biochemically controlled component and a stronger or weaker hormonally controlled diapause component in the early, pre-apolysis (intermoult) part of the moult-intermoult cycle.

\section{Box 9. Stages in the moult-intermoult cycle}

The intermoult period is the period between ecdysis and the subsequent apolysis in the moultintermoult cycle. It is the position of larval diapause.

Apolysis is the hormonally triggered loosening of the old cuticle from the epidermis, which then starts to secrete the cuticle of the next instar under the old one. Separates the intermoult and moult parts in the moult-intermoult cycle. In active development it may take place about half-way between ecdyses.

The moult period is the period between apolysis and the next ecdysis in the moult-intermoult cycle, when the new cuticle is secreted inside the old one. It is non-diapause and little affected by environmental cues or token stimuli.

\section{Diapause presence and functions in odonate larvae}

Larval diapause in dragonflies can occur in several, mostly late stadia of the rather high total number (mostly 9 to 16; Corbet, 2002). It has two partly separate functions, or rather time horizons or anticipation spans for the coming winter, here given separate labels as expanded in Box 10.

In regulatory diapause, moults often have a reduced growth ratio, and can appear supplementary, further reducing growth (e.g. Aoki, 1999; Corbet, 1999, p. 113, 208-212; Corbet, 2002, p. 58; 


\section{Box 10. Diapause functions in odonate larvae}

A pure winter diapause directly prepares for and serves the short-term survival of winter, and winter is always encountered in the affected stadium, often after a short anticipation span probably related to the moulting interval. It sometimes occurs in quite small larvae, but the physiological state of small larvae during winter is uncertain and may comprise different kinds of dormancy (see later in main text).

Regulatory diapause is the core of seasonal regulation in larval Odonata, and the mainstay of regulatory development. It is a complex of slower development with increased moulting intervals, as in the slow cohort after an emergence cohort split. It prevents emergence and is a long-term anticipation of and preparation for winter and is often initiated in summer or even spring (the longday diapause in Norling, 1984c). It usually involves several consecutive stadia, where only the last in the series will actually encounter winter conditions. These regulatory diapauses are highly variable in intensity, and are initially weak and easily overlooked and adjust growth to achieve a correct timing of the preferred overwintering stages (cf. Danks, 2002). Diapauses with related regulatory functions are also discussed by Danks (1987, p. $283-4$ ).

Corbet, Harvey, Abisgold \& Morris, 1989; Ingram \& Jenner, 1976a), but a low growth ratio tend to correlate with an increase in the number of moults which can produce bigger F-0 and so adults (see also Norling, 1984a; Schaller, 1960, p. 765-767; and Funk, Sweeney \& Jackson, 2019, for the mayfly Cloeon dipterum (Linnaeus)).

Regulated and unregulated development was defined by Corbet (1999, p. 220) as diapause present or absent, respectively, which now appears slightly indistinct. A winter diapause may not be necessary if winters can be survived growing or in quiescence. However, in seasonal environments emergence has to be constrained via regulatory diapause-like phenomena. Seasonal regulation in a species can also be achieved via embryonic or pre-reproductive adult diapauses (Corbet, 1999; Suhling, Sahlén et al., 2015) which are outside the scope of the present treatise.

\section{Environmental cues and the induction and termination of larval diapause}

\section{Photoperiod}

Photoperiod, with its astronomical precision, is the most reliable cue for perceiving the time of the year, and so predicting the conditions for growth in the near future (e.g. Danks, 1987; Denlinger et al., 2012). Its effects on diapause are well summarized by Danks (1987, p. 216) and its role in induction and termination of diapause in Odonata is well documented (Corbet, 1999), but many details are still poorly known. Responses to photoperiod in insects may be all or none and switching at a critical photoperiod, which is probably the most common (Denlinger et al., 2012, p.432), or a continuous quantitative response, common in Odonata, with diapause intensities dependent on photoperiod (graded response). In addition, the direction of changes and shifts in photoperiod may be important cues, separating early and late parts of the season (Corbet 1999, p. 229, 2003; Deacon, 1979; Norling, 1984c, 2018).

A dedicated winter diapause is typically induced by short days, present shortly before winter. Also if it is part of the regulatory complex, a short-day induced or maintained winter diapause can normally be terminated by long days.

Induction of regulatory diapause is more complex since winter needs to be predicted far in advance, also on behalf of the adult, nondiapause eggs and small larvae of the next generation, which may be vulnerable (Corbet, 1960; Pritchard, 1982; Pritchard \& Leggott, 1987). Regulatory diapause is often induced and maintained by long days, but it also occurs in other situations. Induction by long days is otherwise a typical characteristic of an aestivation diapause (Masaki, 1980), which is usually preparing for an adverse summer (heat, drought, low food), but here the adversity is a relatively distant winter. A long-day induced regulatory diapause in a pre-final stadium can be temporarily terminated by shorter days, as expanded later (e. g. Corbet 1999, p. 230). 


\section{Temperature}

Thermal induction of larval diapause is less well-known (cf. Danks, 1987, p. 216; Tauber et al., 1986 , p. 135), but probably occurs in Odonata in the winter diapause in smaller larvae (Verheyen, Temmerman, De Block, \& Stoks, 2018; cf. below). The inducing temperature level should be higher than the threshold for development, which will then allow completion of the stadium; otherwise it seems to be quiescence (Norling, 1984c, p. 130). Perhaps some of the minimum temperatures for growth discussed by Suhling, Suhling et al. $(2015$, p. 22), are relevant in this connection. Temperature as the sole predictor of what is ahead is unreliable (Roff, 1983, p. 258), but may work for shortterm prediction, as in larvae with short moulting intervals when temperatures are decreasing slowly, as in milder climates. It is likely to be a dangerous strategy if temperatures are falling rapidly and unpredictably, as at higher latitudes.

\section{Interactions of photoperiod and temperature}

Temperature and photoperiod can interact, sometimes in complex ways to enhance prediction (Hodek \& Hodková, 1988; Roff, 1983). In most insects a short-day induced winter diapause can be counteracted or averted by higher temperatures, whereas long-day induced aestivation diapauses are enhanced by them (e.g. Danks, 1987, p. 114-116; Tauber et al., 1986, p. 138 -139). In some insects, also interactions with other factors such as food are known (Danks, 1987, 2002; Denlinger et al., 2012). Many of these details are yet poorly known in Odonata, and biotic interactions are other possible factors, directly or indirectly affecting diapause induction.

\section{Circannual rhythms}

Circannual rhythms or long-term time measurements have been demonstrated in a few insects, but are possibly more widespread (Danks, 2006; Miyazaki, Nisimura \& Numata, 2014). It is perhaps an element in the perception of changes and could show up as a time window for specific responses to cues and is so worth looking for. It may explain differences in responses during otherwise similar long-term experiments, and assist in telling apart early and late summer in the continuous summer light above the Arctic Circle, as in winter diapause induction in F-1 of Leucorrhinia dubia (Vander Linden) (Norling, 1984b; cf. Visser, Caro, van Oers, Schaper \& Helm, 2010).

\section{Termination by "diapause development"}

During a winter diapause a slow process of termination or progress of diapause ("diapause development") also takes place, often most effective during long-term exposure to autumn and winter conditions (Danks, 1987, p. 149; Tauber et al. 1986 p. 145) (Box 11). In spring, a temperature rise could then restart development from a thermal post-diapause quiescence, allowing synchronization (Danks, 1987, p. 138, 142, 151, 154; Hodek, 2002). At this time, photoperiod may thus be less important or irrelevant for resumption of development in odonate larvae (Corbet, 1999, p. 231; Corbet et al., 1989; Deacon, 1975; Lutz, 1974a; Norling 1971; Sawchyn, 1971, p 133). However, see the later discussion on the importance of winter, and the mathematical model presented by Richter, Suhling, Müller \& Kern (2008), where photoperiod did improve prediction of the onset of emergence in the spring species Gomphus vulgatissimus (Linnaeus). The successive change in response to photoperiod during winter enables development to start in spring, but not prematurely, and underscores the importance of winter as a key event at temperate latitudes. If winter temperatures do not arrive during experiments, diapause will eventually terminate spontaneously and asynchronously after a slow diapause development.

\section{Box 11. Diapause development}

This is a physiological, not morphogenetic process which slowly changes the state of an overwintering animal as diapause development proceeds (Danks, 1987, p. 149; Tauber et al. 1986 p. 145). It successively reduces and often finally eliminates the need for a photoperiodic signal for termination. 


\section{The state of overwintering larvae}

The state of overwintering small larvae is poorly known and may vary. Long-term survival of subthreshold temperatures (below c. $7-8^{\circ} \mathrm{C}$ ) during active development is not likely (e.g. Deacon, 1979; Sawchyn, 1971; Waringer \& Humpesch, 1984), but small larvae are often assumed to overwinter in quiescence (e.g. Eller, 1963). True quiescence seems a particularly likely alternative if winters are mild, as in southern Europe. Here growth can profitably take place during mild periods in winter, and this may also apply to bigger larvae when a winter diapause is not needed for regulation. Winter growth has also been observed or inferred in such situations (Ferreras Romero, 1997; Flenner, Richter \& Suhling, 2010; and Deacon, 1979, in winter-warm New Zealand; cf. also appendix in Paulson \& Jenner, 1971). Winter may even be an important season for growth, in particular in temporary waters and when adults aestivate (see also Suhling, Sahlén et al., 2015, p. 917). In quiescence a cold period should be expected to be spent in any interecdysis stage, and larvae should immediately resume development and moult asynchronously at a temperature increase. Remarkably, F-4 to F-1 Anax junius (Drury), overwintering in Minnesota $\left(45^{\circ} \mathrm{N}\right)$, could start moulting within a day when brought to room temperature, demonstrating that true quiescence can occur even during quite severe winters, but it may compromise survival (Thompson, 2019, p. 37-38). This migratory species is briefly discussed later, and may be outside the present model. Similar observations were made on Ischnura verticalis (Say) in North Carolina, U. S A., at about $36^{\circ} \mathrm{N}$ (appendix in Paulson \& Jenner, 1971).

A thermally induced diapause may be close to quiescence and is so easily interpreted as such. Induction may take place at about $10{ }^{\circ} \mathrm{C}$ (Verheyen et al., 2018) and prevent apolysis and continued moulting. When spring conditions arrive, any diapause is probably terminated, and overwintered early larvae just restart. Overwintering larvae with a $0.7-1.0 \mathrm{~mm}$ head width of Coenagrion puella (Linnaeus), Ischnura elegans (Vander Linden) and Enallagma cyathigerum (Charpentier) from southern Sweden (Supplement 2) moulted relatively synchronously after c. one week when placed in $20{ }^{\circ} \mathrm{C}$, indicating that winter was consistently spent in an early interecdysis stage (own unpublished data). This is expected for diapause, which could be thermally induced since there is no known effect of photoperiod in these sizes (see also section on thermal effects).

An early short-day induced dedicated winter diapause is found at least in some species from northern areas, where quite severe winters can arrive so rapidly that preparation by photoperiodic induction may be necessary, e.g. in A. juncea and L. dubia. In A. juncea such a diapause can be present from a head width of about 1.5 to $2 \mathrm{~mm}$ (roughly F-8; cf. life history in Figure 1h; Norling 1984c). In L. dubia a simple and distinct short-day diapause was shown for F-4 to F-2 (no smaller were tested), all with a consistent "early" response pattern (Norling, 1976; 1984b). The results of Johansson, Sniegula, \& Brodin (2010) suggest that still smaller larvae may be sensitive to short days, and this northern species overwinter successfully in small sizes, even above the Arctic Circle (Norling, 1984b; cf. Figure 1f). In this connection, the important point for survival should be that winter is encountered in a state of diapause, which, if terminated during winter, is continued as a resistant post-diapause quiescence.

\section{A survey of responses and larval development in different situations}

\section{Mode 1. Early development}

Hatchlings are assumed not to display responses predicting emergence. During the season there are three possible outcomes, all realized in Figure 1a. They enter pre-emergence development and emerge if they can reach the critical size before the critical time (Figure 2a). If later, they enter regulatory development, probably in a gradual fashion, and prepare for the last winter (Figure 2b). The third outcome is to encounter winter in early development, also indicated in Figure $2 \mathrm{~b}$. 


\section{a}

b

C

Emergence and metamorphosis (the final, always non-diapause part of F-0)
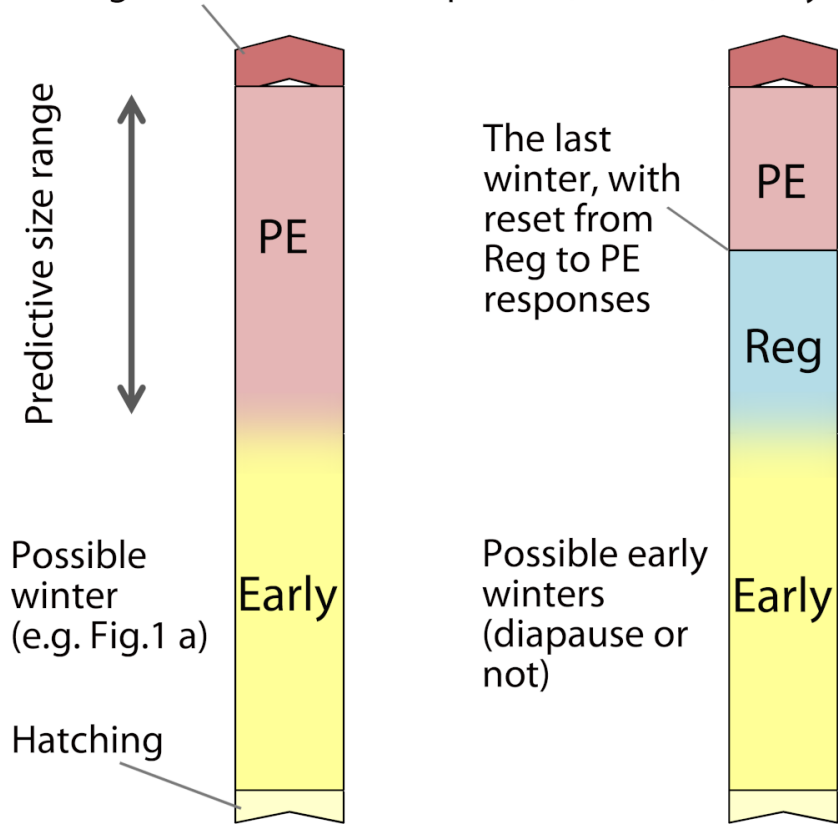

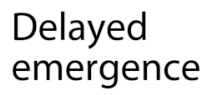

No reset from Reg to PE responses

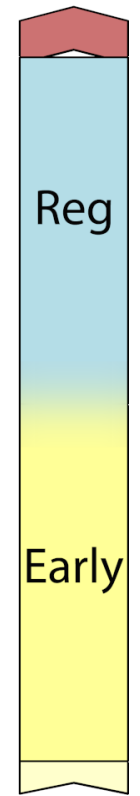

Figure 2. Three examples of response pattern sequences ( $\mathrm{Reg}=$ regulatory, $\mathrm{PE}=$ pre-emergence). Colour coding as in Figure 1 and Table 1. (a) Attainment of predictive size in the year of emergence. Applies to late fliers and mainly low latitudes, often with bi- and multivoltinism (Figure 1a, perhaps b). (b) Attainment of predictive size in the year before emergence. Dominant in early fliers and at high latitudes (Figure 1c-h). (c) A situation common in experimental constant conditions.

\section{Mode 2. Regulatory development}

In regulatory development there is a variable diapause component, preventing emergence and preparing for winter. In the field, all larger larvae should be in a state of regulatory development after the emergence period. Despite reduced growth rate, regulatory development sometimes contributes substantially to total growth, and often occupies a major part of the growth season before the last winter (Figure 1c, d, g). It often appears to take place at an approximate half-speed, perhaps regarded as routine development.

The regulatory responses in different sizes/stages appear to be adapted to the photoperiodic and thermal regime to guide larvae through the season to a preferred size/stage for winter. In other words, the distribution of regulatory delay among stadia should differ between photoperiods. The strength of the diapause component is likely to be continuously adjusted with the help of information from seasonal cues and larval size. This produces the convergence on a suitable size range for the last winter (cf. Danks, 1987, p. 209) which often leads to a merging of cohorts of different ages above the WCS ("Ov" in Figure 1). The regulatory diapauses are strongest in long days and in big sizes (time surplus; the leading edge of regulatory development; e.g. Norling, 1971, 1984a). On the other hand, a late-season transition from early development is indistinct and these smaller predictive sizes at first grow relatively fast in the shorter late summer - early autumn days (time constraint for attainment of the last winter; trailing edge of regulatory development). Faster regulatory growth in shorter endseason photoperiods is seen in different experimental approaches (Mikolajewski, De Block \& Stoks, 2015; Norling, 1971, 1984a; Śniegula, Johansson \& Nilsson-Örtman, 2012). Regulatory larvae normally encounter winter with a short-day maintained winter diapause above the WCS. However, as pointed out above, during mild winters diapause may not be necessary as long as untimely emergence is prevented. When the regulatory complex is concentrated to F- 0 , as in the spring species $L$. dubia (Norling, 1976, 1984b, c), there is a similar synchronizing intrastadium sequence in diapause 
intensity as otherwise among stadia, but here it appears as a variation of the pre-apolysis morphogenetic rate.

A long-day regulatory diapause often weakens or terminates transitorily when days are shortening. In populations with many larvae overwintering in F-0, an intense summer diapause in F-1 is sometimes terminated synchronously by shorter days towards the autumn, when larvae moult to a winter diapause in F-0 (e.g. Aoki, 1999; Corbet 1999, p. 230; Corbet \& Harvey, 1989; Corbet et al., 1989; Lutz, 1974a, b; see also the striking field data in Di Giovanni, Goretti, La Porta \& Ceccagnoli, 2000). This pattern is present in Epitheca cynosura (Say) (Figure 1e), to some extent in C. hastulatum (Figure 1d; Norling, 1984a), but is absent in L. dubia (Figure 1f), where the summer diapause is extremely weak in F-1 and mainly located in F-0 (Norling, 1984b). These shorter days were assumed to be equinoctial in the cited works, but they are more likely to be dependent on the local climatephotoperiod relationships in the manner of a critical photoperiod. To prevent emergence, a regulatory summer diapause in F-0 has to continue without moulting as a short-day maintained winter diapause (Figure 1f). This sometimes happens also in F-1 in late species, e.g. A. viridis (Figure 1g; Norling, 1971), which counteracts overwintering in F-0. In general, spring species can be expected to have more intense regulatory diapauses in each stadium than summer species due to shorter emergence windows (more delay needed) and responses present in fewer stadia.

In the mayfly Cloeon dipterum prevention of an untimely late-season emergence takes place via responses very close to odonatan regulatory development, also displaying increased moulting intervals, lower growth ratios, and bigger adults (Funk et al., 2019), but in this short-lived, multivoltine species it is induced by short days reinforced by cool temperatures.

In summary, regulatory development in Odonata is a period of variably delayed development where size and environmental cues interact to determine the phenologically important stadium composition during the last winter. Details in regulatory development, including the WCS, are thus of particular importance in phenology and in latitudinal adaptation.

\section{Mode 3. Pre-emergence development}

This development mode can be reached directly after early development in some late fliers such as $E$. aspersum and I. elegans (Figure 1a, 2a, probably 1b). However, pre-emergence development often starts after a winter reached during regulatory development (Figure 1a-h, 2b). The complexities of this transition, from regulatory to pre-emergence development, are discussed separately below.

Pre-emergence development is accelerated by long summer days, perhaps sometimes also by decreasing long days (high perceived time constraint; cf. Norling, 2018), as compared to the more moderate effect of shorter early spring photoperiods (Norling, 1971, 1984a). Much of this variation in the rate of pre-emergence development seems concentrated to the pre-apolysis (intermoult) part of the moult-intermoult cycle and controlled like diapause (unpublished observations, cf. Box 8). A different mechanism, perhaps related to enzyme kinetics and concentrations of participating molecules (cf. Clarke, 2003; Seebacher, et al., 2010) could contribute and be active also after apolysis, as indicated for L. sponsa (Norling, 2018) and L. dubia (Norling, 1984b). Faster development can also correlate with reallocation of other resources to growth (Stoks et al., 2012). A period of pre-emergence development is always present at the end of a natural larval development (Figure 1,2), although very short in early species.

\section{The reset to pre-emergence responses and the importance of winter}

In colder temperate climates the winter period is a key event in seasonal regulation. It has to be prepared for and survived in all affected sizes. It is the time of a short-day mediated reset from regulatory development to pre-emergence responses and is so an important time setter. The reset by the exposure to short days is assisted by low temperatures and can perhaps even be replaced by them (Ingram, 1975; Lutz, 1968b, 1974b). In autumn, pre-emergence development is at first prevented by diapause-maintaining short days, and later also by low temperatures. During this time, diapause is 
also slowly terminated by diapause development at low temperatures, priming the subsequent responses to spring conditions as described above (Lutz, 1968b, 1974a, b; Corbet, 1999, p. 232).

Together, the phases of the two-step reaction, centred on the reset to pre-emergence development, can work like the gates of a lock in a canal, a metaphor of the WCS model which is described in Figure 3. However, the reset to pre-emergence development may be more variable and complex than described if responses adapted to a temperate climate evolved separately in different lineages. Also, there are occasional and unexplained failures of an increase in photoperiod to start pre-emergence development from short days in long-term experiments without low temperatures (a couple of own unpublished observations; Sackville, Brauner \& Matthews, 2019), although this is otherwise successful. Or - could circannual rhythms be involved?

\section{Early and regulatory development Pre-emergence development}

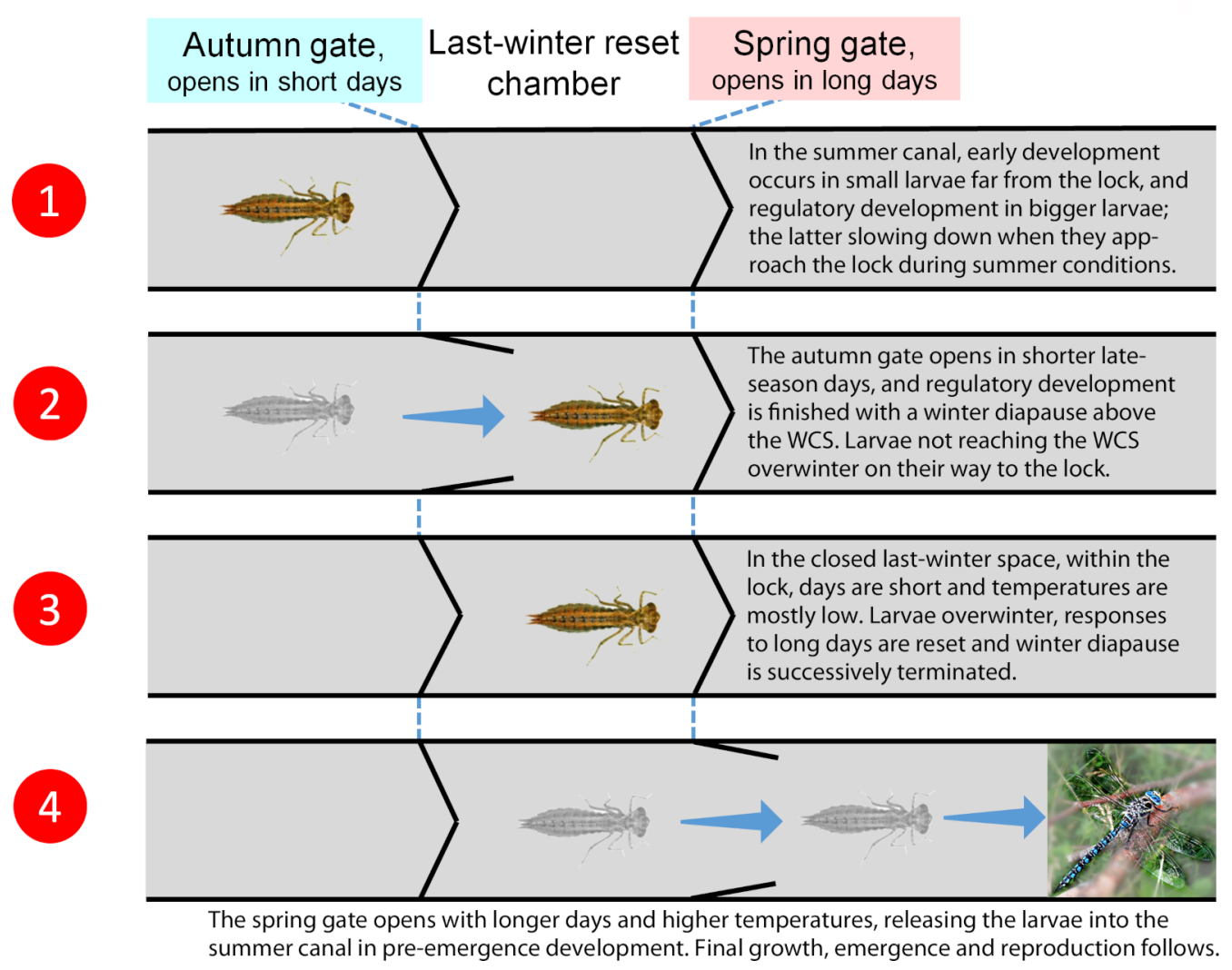

Figure 3. The "winter critical size lock in the summer canal", a simplified metaphor of the two-step seasonal regulation at higher latitudes. It also illustrates how constant conditions can trap larvae at one of the gates in the two-step lock (compare Figure 2). Importantly, this metaphor does not include plasticity of the WCS, or a later critical time, e.g. in bivoltinism. The latter requires free passage through both gates at some time during the summer.

Overwintering larvae in regulatory development should by definition (the last winter) be above the WCS in spring. They start pre-emergence development at the step-up in photoperiod and temperature, which indicate a restart from a spring minimum of time stress (Figure 2b). However, the plasticity of the WCS illustrates the indistinctness of the predictive range and the early - regulatory/preemergence interface. An extremely late spring in a cold place can force specimens overwintering just above the normal WCS into what very indistinctly appears to be "renewed" or "continued" regulatory development, and conversely, a warm early spring could allow smaller overwintering larvae to go for emergence. 
Despite ongoing diapause termination during winter, remaining diapause may still have some importance in spring, modulating the sensitivity to photoperiod and maybe to temperature. If diapause is more incompletely terminated in bigger larvae, these may need a stronger photoperiodic or thermal signal at this time and so initiate development later than somewhat smaller larvae. Such synchronizing differential diapause termination was shown by Eller (1963) and Sawchyn (1971, p. 140), but the effect must be the same as that of the rising lower temperature thresholds in successively later stadia proposed by Corbet (1957b). The latter was subsequently demonstrated for Lestes eurinus Say (Lutz, 1968a, b) and likely for Leucorrhinia intacta Hagen (Deacon, 1975, p.70), but not for the potentially winter-growing Xanthocnemis zealandica (McLachlan) despite careful examination (Deacon, 1979, p. 162). These proposed mechanisms, also later discussed by Corbet (1999, p. 232), may just be different aspects of a single mechanism integrating size-dependent diapause, photoperiod and temperature, but it remains to be demonstrated (cf. Tauber et al., 1986, p. 24). In addition, a contribution from stadium specific thermal coefficients was discussed by the above authors, but also this can be an effect of temperature-diapause interactions (see the section on thermal effects below).

A significant implication of the importance of winter is that a short experimental winter treatment of just a couple of weeks is probably leaving the larvae in an autumn state, which then requires extra photoperiodic activation, insidiously delaying development under otherwise normal spring conditions.

\section{The role of changes, constancy and absolute levels of photoperiod}

\section{Direction of changes versus absolute photoperiods}

There are scattered indications that the magnitude of the photoperiodic increase itself is particularly important for the final reset to pre-emergence development. Pre-emergence development is first seen in the most advanced larvae when exposed to extreme long-day photoperiods in late summer experiments (Norling 1971; 1976; 1984c). Generally, in responses to changes in other contexts, increases amplify long-day responses and decreases amplify short-day responses, with a possible exception for a late summer acceleration of emergence (Norling, 2018 and references therein). The development rate at a particular photoperiod in early regulatory development in F-0 L. dubia was that of a shorter day (i.e. faster) if larvae were transferred to this photoperiod from a longer day (Norling, 1976). Late regulatory development was always slow. Also, the critical photoperiod for a pure winter diapause in pre-final stadia of $L$. dubia was higher in late summer than in overwintered specimens, even after the first 1-2 moults, which seem to depend on recent changes (Norling, 1984b; see also discussion in Norling, 1976). In Supplement 1, variation in final stadium winter diapauses in C. hastulatum and $A$. viridis are described in a related context.

In view of the poor state of knowledge, the following summary is highly tentative. Absolute photoperiods are probably important in induction of a dedicated winter diapause in early development, and also in regulatory development, although the latter responses vary ontogenetically and sometimes differ little between photoperiods (e.g. Norling, 1976). These effects of absolute photoperiod can be modified by changes (temporal progress), e.g. by displacing a critical photoperiod for a frequently graded response. Then, changes should mainly be effective in an intermediate photoperiodic range. Hypothetically, such differences in thresholds for cues after changes could be related to some kind of earlier environmental "imprinting" in larvae or even in eggs. However, termination of the state of regulatory development requires obligatory increases, perhaps largely independent of absolute photoperiod.

\section{Effects of long-term constant conditions}

The seasonal progression of photoperiod and temperature is a natural background for the correct timing of seasonal events. Larvae experimentally kept in constant photoperiods and temperatures from small sizes receive no cues of seasonal progress. This, and contradictory cues, e.g. high sum- 
mer temperatures and long-term autumn-winter photoperiods, may cause a confused or ecologically irrelevant response (Norling, 2018; cf. Danks, 1987, p. 116-117). Larvae under persistently constant conditions often appear to enter a regulatory development which is never reset. They probably start long-term preparations for winter, but the winter is continuously and indefinitely postponed, and they tend to emerge with a variable and often irregular delay after spontaneous diapause termination (Figure 2c). The function of regulatory development to guide larvae through the season to a suitable overwintering stage can be expected to be disturbed.

In the field, regulatory development starts when the critical size is reached after the critical time (Figure 1). In WCS populations, with the critical time early in spring (Figure 1c-h), constant conditions should then mimic a post-critical attainment of the critical size, with regulatory preparations for the last winter (Figure $2 \mathrm{c}$ ). This is only reset to pre-emergence development after the autumn - winter - spring sequence (see also Figure $2 \mathrm{~b}$ ), which is hardly simulated by any long-term constant conditions. On the other hand, if the critical time is late, as in asynchronous fast-growing populations with a capacity for bi- and multivoltinism, some constant conditions might simulate a pre-critical attainment of the critical size, with time constraints directly allowing different rates of pre-emergence development (Figure 1a, 2a).

A moderate regulatory reduction in growth rate in experiments can be difficult to detect without pre-emergence control groups, and growth is often presented in a manner which is difficult to compare with other data sources. These problems are further documented in the section on thermal effects below, and in Supplement 5. One possible indication of diapause phenomena is widely variable individual development rates in predictive-range larvae (well exceeding a factor of $2-3$ ), which may arise from a variable diapause component terminating spontaneously; another is excessively slow growth rates compared to nondiapause "early" larvae (note that F-0 is always relatively long; cf. Corbet, 2002). Low thermal optima for growth $\left(<25^{\circ} \mathrm{C}\right)$, diverging from those of smaller larvae, can be a third indication, also discussed later in the section on thermal effects, where Figure 7 and its expansion S2b in Supplement 2 can illustrate all three criteria.

Common coenagrionid model species, e.g. Coenagrion puella (Linnaeus) and Ischnura elegans (Vander Linden), are at least partly or mostly univoltine in northern Europe (Figure 1b, c; Corbet et al., 2006; own unpublished observations). If these species take appreciably more than $4-5$ months from hatching to emergence at experimental summer temperatures $\left(\right.$ c. $\left.20^{\circ} \mathrm{C}\right)$ they are probably displaying some kind of growth restrictions which could be regulatory diapause (conservative estimate from own data on nondiapause stadium durations). The whole life cycle, including maturation, reproduction and egg development will then not fit into one year in northern Europe, where summer conditions prevail for less than 5 months (May - September). For example, the development times for $I$. elegans from $55^{\circ} \mathrm{N}$ reported by Stoks \& De Block (2011, in Supplement) appear too long (6-7 months at LD 14:10 and $21-24{ }^{\circ} \mathrm{C}$ ) and should be subject to some delaying factor.

The growth of Coenagrion armatum (Charpentier) and Coenagrion pulchellum (Vander Linden) in medium to late stadia at LD $14: 10$ and $21^{\circ} \mathrm{C}$ reported by Nilsson-Örtman, Stoks \& Johansson (2014) seems distinctly regulatory and is close to the regulatory semivoltine development between the first and second winter, mainly documented in related species (Figure 1c-d; C. armatum in Johansson \& Norling, 1994).

When changes are important, we can ask to what extent responses during persistently constant conditions are ecologically relevant, and, if so, exactly what normal episode in the life history they are relevant for. What does it mean that cues are constant, but larvae develop? For example, the same static conditions may give a different message to larvae in F-3 than later in F-0 (cf. Supplement 1). As suggested above, the absolute photoperiod may still be important, influencing the particular response in different sizes. Constant end-of-summer photoperiods may generally be more permissive than both longer and shorter days, in particular around the WCS as in fast regulatory development (Norling, 1971, 1984c). Such intermediate photoperiods are transitional in the field, and during late season they are preparatory to shorter days and lower temperatures, and they can still be expected to delay emergence in big larvae.

To conclude, it is important to take the effects of constant conditions into account when rearing larvae, in particular from an early stage to emergence. However, for limited periods, development in constant conditions seems to simulate natural development quite well. Sudden constant summer conditions directly after a natural winter have faithfully replicated a spring cohort split with naturallooking pre-emergence and regulatory cohorts (see section on the WCS model). A discerning use of 
constant conditions, with control of the response patterns, should be an excellent approach for many kinds of study.

\section{Thermal effects on development in the different response patterns}

\section{Temperature, diapause and development}

Temperature is directly affecting growth, but it is also a cue or token stimulus for seasonal regulation. Photoperiod and temperature can interact in complex ways in induction, maintenance and termination of diapause (e.g. Hodek \& Hodková, 1988). The coin of these interactions has two sides: when temperature affects the responses to photoperiod, it follows that photoperiod will affect responses to temperature (e.g. Danks, 1987, p. 116). The latter kind of interaction has been described also from non-diapause larval stages in many other insects (e.g. Gotthard, Nylin \& Wiklund, 2000; Kutcherov, Lopatina \& Kipyatkov, 2011; Lopatina, Kipyatkov, Balashov \& Kutcherov, 2011; see also Nylin, Wickman \& Wiklund, 1989).

Some of the intricacies of the interactions between temperature and diapause-related phenomena in larval development are outlined in Figure 4. Diapause is governed by both photoperiod and temperature as seasonal cues, and the rate of growth and development is always reduced in diapause. High temperatures can both decrease and increase the incidence and intensity of diapause, depending on its function (see section on diapause and interactions). Then, high-temperature effects on growth become complex: temperature in a normal viable range accelerates active growth biochemically, but if the effects of temperature on the diapause component are superimposed on this, we can have a range of observed composite effects on growth and development. This kind of situation was previously proposed by Pritchard et al. (1996) for egg development in other water-living exopterygotes. Finally, growth causes a feedback on this system. When larval size increases, the presence and properties of diapause change, causing ontogenetic shifts in responses, connected to seasonal regulation.

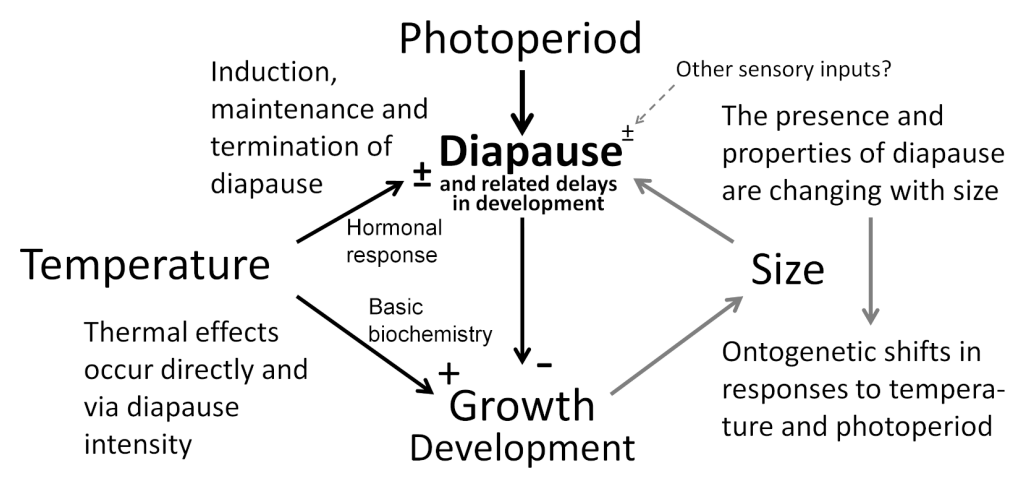

Figure 4. Graphical presentation of the complexities of thermal responses during larval development: interactions between growth and development, diapause in its widest sense, temperature, photoperiod and size. Legend : + increase or amplification; - decrease or reduction; \pm variable effect

Development rate as governed by the hardware of basic biochemistry may be physiologically constrained and evolutionary conservative (Angilletta, 2009; Pritchard et al., 1996; Tüzün \& Stoks, 2018). However, within the diapause component, development is hormonally controlled from the brain where environmental cues, and perhaps other sensory inputs such as the presence of food, predators and competitors, can be received and integrated by the neural software. In this way plasticity of thermal responses, including shifts in performance curves and ontogenetic changes, could evolve without changes at the level of enzyme activity, but achieved by selective damping. Intuitive reasoning suggests the following assumptions for the different response patterns, diagrammatically illustrated in Figure 5 and also entered in Table 1. 


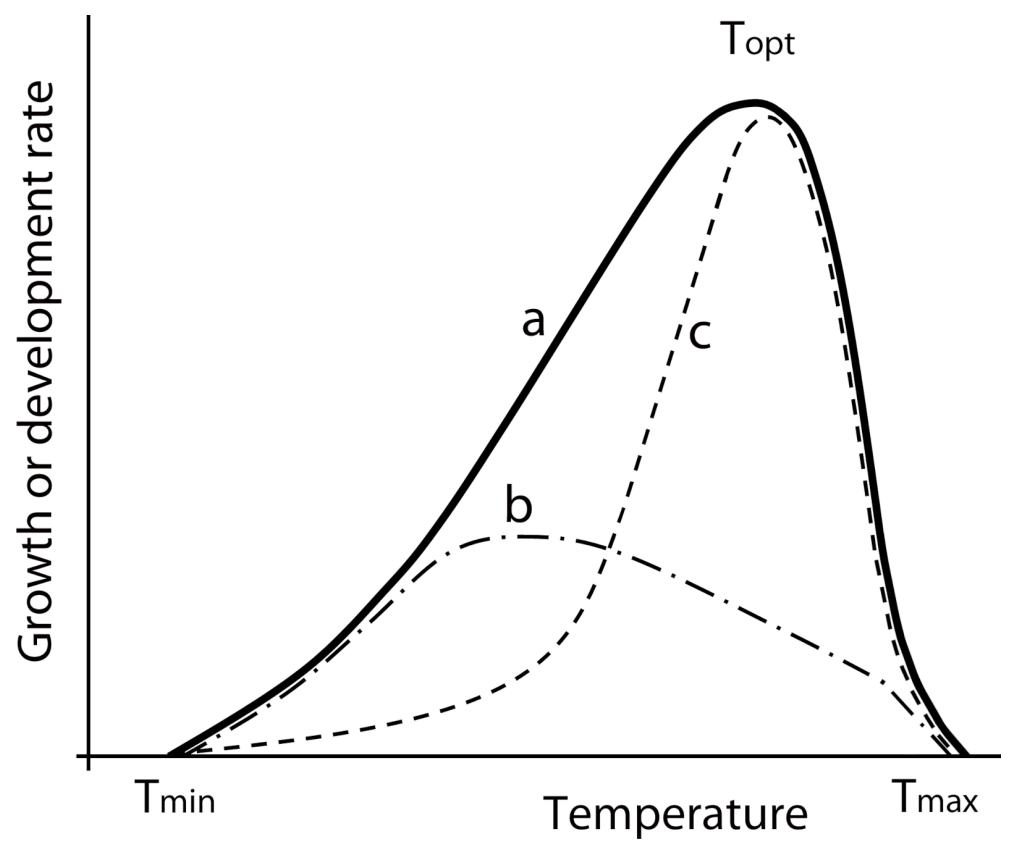

Figure 5. Hypothetical thermal performance curves showing possible effects of diapause-temperature interactions on growth/development rate (the inverse of development time shown in Figure 6a, 7, S2b and S4). (a) Active, non-diapause development (pre-emergence and early) assumed to represent biochemical processes in a relatively direct manner. (b) Regulatory development with diapause component strengthened at higher temperatures. The actual curve can be expected to be dependent not only on species and population, but also on stage and photoperiodic cues, even within a population. (c) Early development with photoperiodically induced winter diapause, averted at high temperatures.

\section{Mode 1. Early development}

During this supposedly undetermined start of development, a rather general thermal performance curve, mainly dependent on biochemical constraints and with a high optimum temperature can be expected, to shorten development time (a in Figure 5; cf. Dell, Pawar \& Savage, 2011). As noted previously, a photoperiodically induced dedicated winter diapause, which can occur here, is often counteracted by high temperatures, which then will appear to further steepen the reaction norm at higher sub-optimum temperatures ( $\mathrm{c}$ in Figure 5).

\section{Mode 2. Regulatory development}

Although the inception of regulatory development is counteracted by high temperatures, for example seen in the plasticity of the WCS, a flat or attenuated thermal response seems appropriate when this mode is well established. In time surplus, high temperatures should not accelerate development to premature emergence, and low temperatures, in particular if combined with a shorter growth season, should not impede the possibilities to reach a suitable stage for the last winter. This stage in a cold place may even need to be more advanced to compensate for a plastically larger WCS. It can then be argued that the temperature response should even become inverse already well below the biochemical optimum (b in Figure 5), which occurs during an aestivation diapause (e. g. Danks, 1987, p. 114; Tauber et al, 1986, p. 139-140). We could therefore expect a spectrum of temperature responses depending on the diapause component in development.

\section{Mode 3. Pre-emergence development}

A steep thermal response is speeding up development at high temperatures, in particular under time stress, when the costs of fast development can be accounted for (Gotthard et al., 2000). A thermal performance curve similar to that in early development can be expected (a in Figure 5). 


\section{Testing the assumptions: comparisons of old and new data}

The prediction that the temperature reaction norm during less time constrained development should be flatter than under a strong time constraint was successfully tested by Gotthard et al. (2000) in the butterfly Lasiommata maera (Linnaeus). To test the above predictions in dragonflies a couple of small exploratory experiments on C. puella were performed and compared with published data, and some old unpublished data on $A$. juncea and $C$. hastulatum were re-analysed (see methods and other details in Supplement 2). Although the compared populations of Coenagrion have different latitudinal origins, this does not seem to have had any fundamental impact on the results.

\section{Coenagrion puella and $C$. hastulatum}

Waringer (1982) and Waringer \& Humpesch (1984) studied thermal effects on development in $C$. puella $\left(48^{\circ} \mathrm{N}\right.$; see grey background in Figure $\left.6 \mathrm{a}\right)$. The stadia $2-8$ (the prolarva counted as the first), evidently in early development, grew fast and showed a monotonous decrease in moulting intervals between 12 and $28^{\circ} \mathrm{C}$, seemingly unaffected by the used constant photoperiods (LD 10:14, 12:12 and continuous light, LL; Waringer, 1982). On the other hand, the stadia $9-12$ (F-3 to F-0), evidently in the predictive range, showed a variable and slow development suggesting regulatory diapauses, and an essentially flat or inverse temperature response.
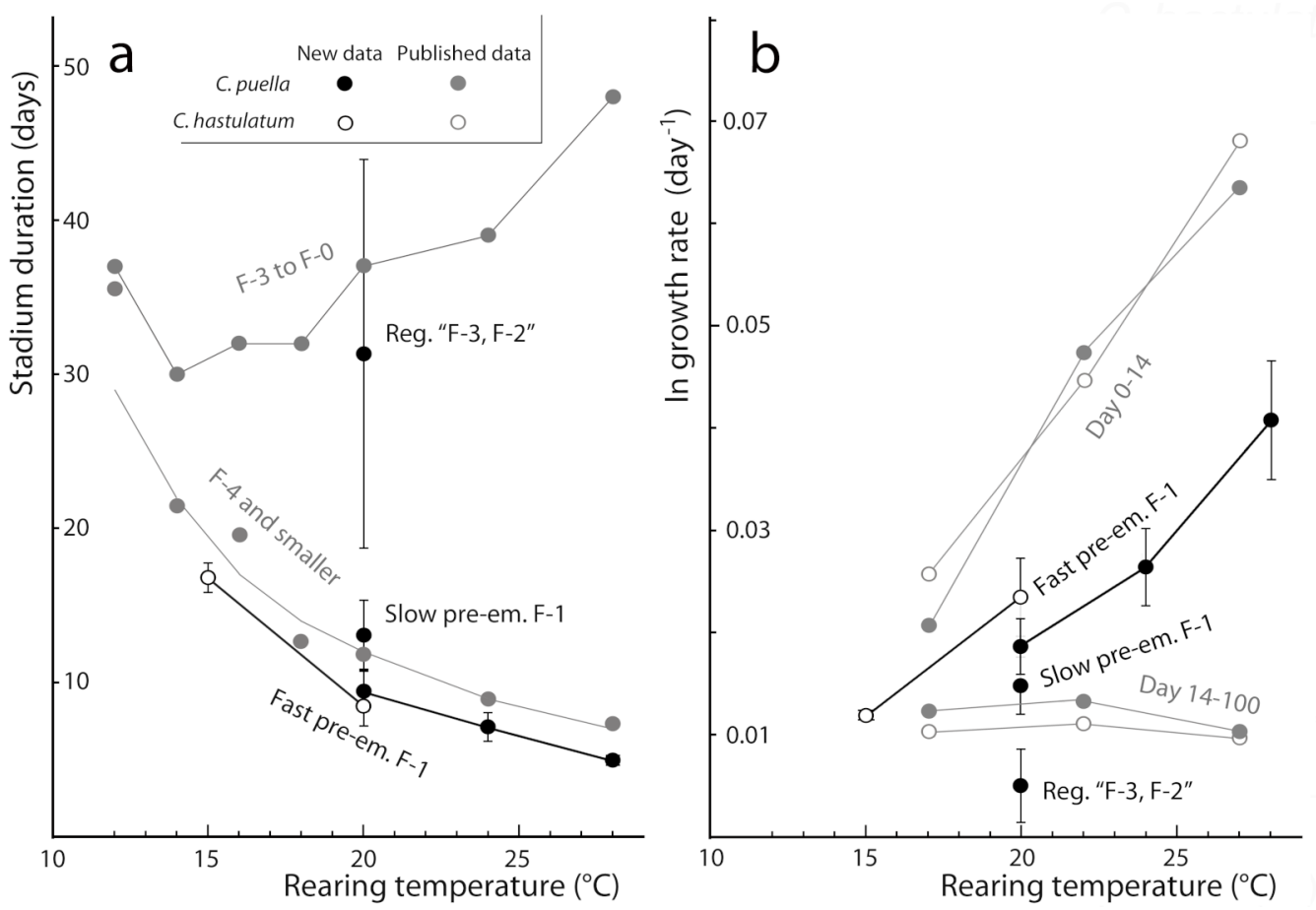

Figure 6. Thermal responses in larvae of $C$. puella (filled) and $C$. hastulatum (open). Own data (black, with standard deviations) are shown together with data from the literature (shaded). Own data are from Sweden, $58^{\circ} \mathrm{N}$ (see Supplement 2). (a) Moulting intervals of different stadia and stadia groupings in different temperatures. Literature data are from Austria ( $48^{\circ} \mathrm{N}$, C. puella only), based on Waringer (1982). Big larvae and smoothed curve for small larvae (power function) are derived from data in his table 7 ; data points of small larvae are back-calculated from his figure 9. Photoperiods were constant LD 10:14, 12:12, or LL. (b) Daily growth rates based on head width ( (In end size - In start size) $\times$ duration $\left.^{-1}\right)$ in different temperatures. Literature data are from Belgium (C. puella, $50^{\circ} \mathrm{N}$ ), and Sweden (C. hastulatum, $63^{\circ} \mathrm{N}$ ), rearranged from van Doorslaer \& Stoks (2005a). Data from two intervals after hatching are shown: $0-14$ days (upper graph) and 14-100 days (lower graph). Experimental photoperiod was constant LD 14:10. Own data were calculated from growth during the moulting intervals also shown in (a). Number of specimens per treatment in own experiments varied between $4(C$. hastulatum $)$ and $8-15(C$. puella); see details in Supplement 2. 


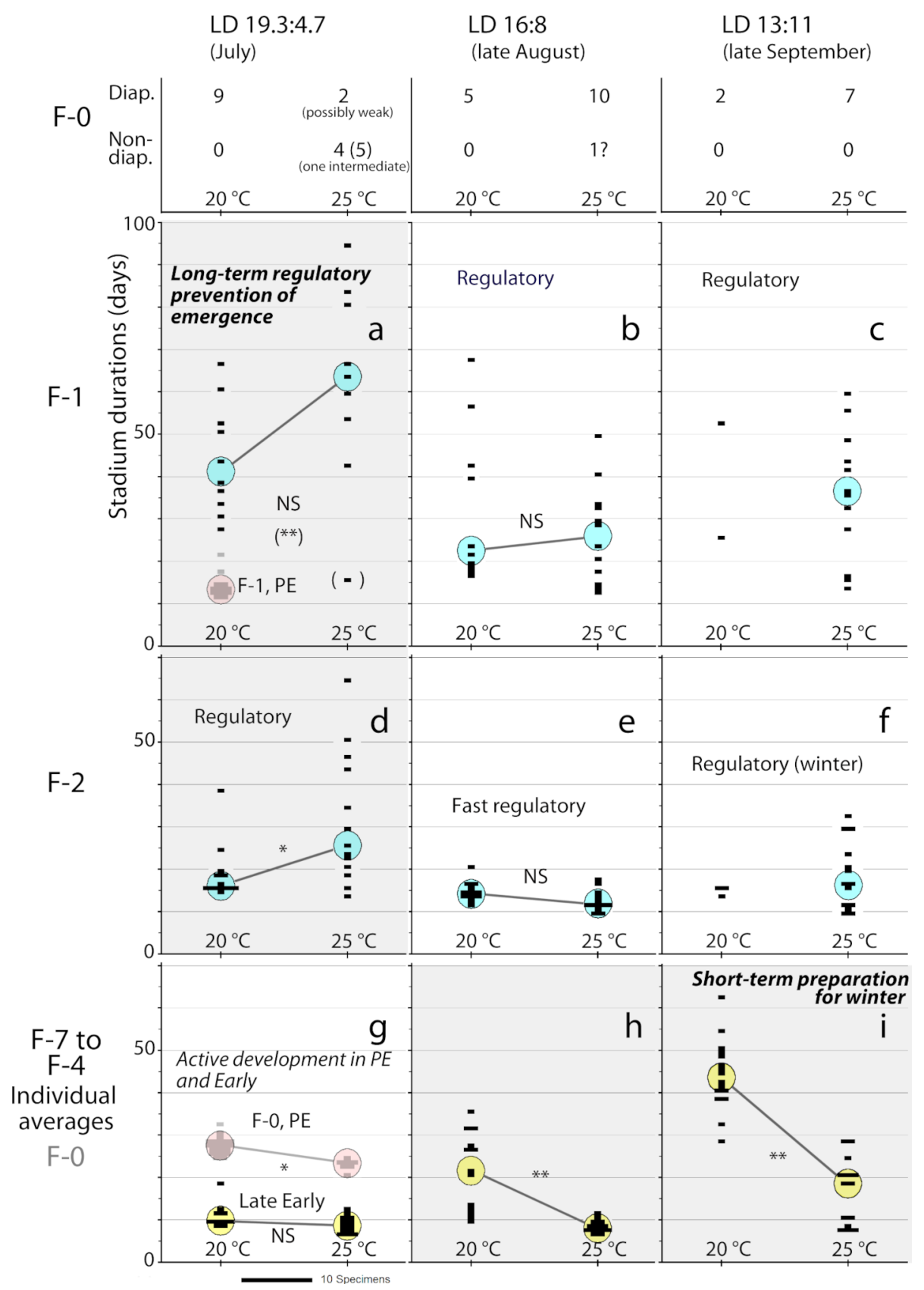

Figure 7. Diapause-temperature interactions in $A$. juncea $\left(58^{\circ} \mathrm{N}\right)$. Stadium durations with medians at two temperatures and three constant photoperiods in a six-month experiment, starting in August 1974 with larvae in F-8 to F-6. These data should represent early (yellow) or regulatory (blue) development. For F0 , duration was rarely recorded but the occurrence of diapause could usually be assessed, as shown above the graphs. Some pre-emergence (PE) durations of $F-1(a)$ and $F-0(g)$ from other experiments are shown as pale pink symbols. Results from Mann-Whitney U-tests between temperatures are shown as **, * and NS ( $P<0.01, P<0.05$ and not significant, respectively). In (a), a result with removal of the sole nondiapause specimen is shown, both in parentheses. See Supplement 2 for more detailed information and an extended version of the graph.

In Figure 6a, own data on $C$. puella from Sweden $\left(58^{\circ} \mathrm{N}\right)$ show that long-day diapausing regulatory stadia at $20{ }^{\circ} \mathrm{C}$ and LD 20:4 were very variable in duration (Reg. "F-3, F-2") and coinciding well with Waringer's (1982) data for F-3 to F-0, but they also displayed supplementary moulting. At the 
same time long-day accelerated (also LD 20:4) pre-emergence late stadium Swedish larvae ("Fast pre-em F-1"; see also F-0 in Supplement 3) were following the thermal responses of early-development larvae, not indicating any ontogenetic shift. Pre-emergence F-1 larvae from a shorter, less time constraining photoperiod (LD $16: 8 ; 20^{\circ} \mathrm{C}$ only) were slower, but still close to the small larvae ("Slow pre-em. F-1"). Also, the old pre-emergence data for F-1 and F-0 in C. hastulatum followed these patterns (Figure 6a; Supplement 3; Norling 1984a).

Van Doorslaer \& Stoks (2005a) studied temperature and growth rate in C. puella $\left(50^{\circ} \mathrm{N}\right)$ and $C$. hastulatum $\left(63^{\circ} \mathrm{N}\right)$ at a constant photoperiod of LD 14:10. Some of their data are presented as a background in Figure 6b. Growth rate in early development during the first two weeks after hatching increased in a steep and rather linear fashion between 17 and $27^{\circ} \mathrm{C}$. Between day 14 and 100 , when the biggest larvae reached F-2 or F-1, thus reaching well into the predictive size range, they grew slowly with a relatively flat response, and appeared largely regulatory. However, at $17^{\circ} \mathrm{C}$ they started at small sizes, and they probably barely touched the predictive size range, affecting comparisons between temperatures. Own F-1 pre-emergence data from both species $\left(58^{\circ} \mathrm{N}\right)$ instead showed similar thermal responses as the non-diapause hatchlings, but with a lower overall growth rate (longer stadium durations, probably lower growth ratios; Corbet, 2002). Thus, active development in these species as seen in both early and pre-emergence development have similar steep thermal responses, different from the flat or inverse responses in regulatory development.

Van Doorslaer \& Stoks (2005b) also measured daily weight increase in these two species during four days after ecdysis into F-3 and F-2, under constant LD 14:10. In C. puella $\left(50^{\circ} \mathrm{N}\right)$ at $17-27^{\circ} \mathrm{C}$, the weight increase was roughly between 2 and $4 \%$ during these four days, and in C. hastulatum $\left(63^{\circ} \mathrm{N}\right.$ ) it was between 4 and $10 \%$ (back-calculated from figure 1a in Van Doorslaer \& Stoks, 2005b). All these larvae were clearly diapausing, with the most intense diapause at the highest temperature. In own experiments on pre-emergence C. puella $\left(58^{\circ} \mathrm{N}\right.$, LD $\left.20: 4\right)$ reaching these stadia, four days was the mean moulting interval at $28{ }^{\circ} \mathrm{C}$ (range $3.0-4.5, \mathrm{~N}=9$; cf. 5 days for $\mathrm{F}-1$ in Figure $6 a$ ), which may roughly correspond to a $70 \%$ weight increase (volume increase at a linear growth ratio of 1.2). This is to be compared with $2 \%$ for C. puella and $4 \%$ for C. hastulatum at $27^{\circ} \mathrm{C}$ in the mentioned study.

\section{$\mathrm{F}-0$ in two spring species}

In Supplement 4, the combined effects of photoperiod and temperature on the intensity of F-0 regulatory diapause in two spring species, L. dubia and E. cynosura are discussed and analysed (Figure S4; Norling, 1976; Lutz 1974a; cf. life histories in Figure 1e and f). Diapause, seen as durations of parts of F-0, is also here amplified at higher temperatures, whereas non-diapause and often low-diapause durations are decreasing with temperature, giving Figure S4 a similar appearance as Figure 6a.

\section{Aeshna juncea}

In Figure 7, a more complex picture of growth-temperature interactions is shown in an old unpublished constant-photoperiod experiment on A. juncea from $58^{\circ} \mathrm{N}$, from the same population as Figure $1 \mathrm{~h}$. Unfortunately, few replicates and often a high variance make the results only partially statistically significant. See Supplement 2 also for an extended discussion.

At a summer photoperiod (LD 19.3:4.7, late May or July), F-1 and F-2 on the whole showed a variable regulatory development with longer stadium durations when diapausing at $25^{\circ}$ than at $20^{\circ} \mathrm{C}$ (Figure 7a, d). In 7a, pale pink symbols also show the considerably faster pre-emergence F-1 development at $20^{\circ} \mathrm{C}$. These results are in accordance with the mentioned assumptions. At the same photoperiod, smaller (F-7 to F-4) larvae in early development, and pre-emergence F-0 from other experiments were non-diapause, with a probably slightly faster development at $25^{\circ} \mathrm{C}$ (both in Figure $7 \mathrm{~g}$ ). The overall picture of thermal effects in different sizes is also here reminiscent of that in Figure 6a. Remarkably, F-0 often showed weak or no diapause at the higher temperature, even after diapause in the preceding stadia (table at top of Figure 7). The latter reminds of the situation described for $A$. viridis and C. hastulatum in in Supplement 1.

In an end-of-summer photoperiod (LD 16:8, late August), F-1 responses were highly variable but mostly diapause at both temperatures (Figure 7b), while F-2 (7e) appeared non-diapause and seemed faster at the higher temperature, probably in a state of fast regulatory development, since overwintering F-2 could be both above and below the plastic WCS in this population, depending on springsummer thermal conditions ( $\mathrm{cf}$. Norling 1984c). However, in early development many larvae showed 
the beginning of a winter diapause in some moulting intervals at $20{ }^{\circ} \mathrm{C}$, while all were non-diapause at $25^{\circ} \mathrm{C}$ (Figure $7 \mathrm{~h}$; see also $\mathrm{k}$ in Figure S2b in Supplement 2). This steepened the average temperature response.

In an autumn photoperiod (LD 13:11, September), there was a strong winter diapause in nearly every moulting interval in early development at $20{ }^{\circ} \mathrm{C}$, but a weaker and partial one at $25{ }^{\circ} \mathrm{C}$, again giving a steepened slope (Figure 7i, see also 1 in Figure S2b in Supplement 2). At $20{ }^{\circ} \mathrm{C}$ only a few fast larvae reached later stadia during the six-month experiment, making meaningful comparisons between temperatures impossible in F-2 and F-1, although there was a high incidence of diapause at $25{ }^{\circ} \mathrm{C}(7 \mathrm{c}, \mathrm{f})$. However, it should be noted that even short-term $25{ }^{\circ} \mathrm{C}$ in autumn is extremely unlikely at $58^{\circ} \mathrm{N}$, and long-term it may be more of physiological interest than of ecological relevance.

\section{Implications of the presented data}

On the whole, the data presented above support a flat or even negative reaction norm to temperature during slow regulatory development, reminding of an aestivation diapause. These responses are preventing premature emergence also at high temperatures. Contrary to this, the thermal responses of early $A$. juncea larvae during late-season photoperiods were both positive and exaggerated, but this originates from an interaction pattern of a pure winter diapause. This illustrates the different time horizons or prediction ranges for these diapauses. For a pure winter diapause in early larvae, high temperatures might allow another moult before winter, but high late summer - autumn temperatures do not allow the start of another generation for any larval size. Therefore, even a short-day maintained regulatory diapause could be expected to have a flat or negative temperature response, at least in the most advanced sizes. However, unseasonably late emergence, probably from regulatory development, can sometimes be correlated with very hot weather (e.g. Fliedner \& Fliedner, 2000) which seems contradictory. Perhaps high temperatures can make diapause break down in very advanced larvae after an earlier period of intense diapause (cf. F-0 in Figure 7, and a similar effect of $25^{\circ} \mathrm{C}$ in advanced F-0 substages in L. dubia; Norling, 1976).

Some of the thermal optima reviewed by Suhling, Suhling et al. (2015) may be somewhat low in many Coenagrionidae and originate from big or medium-sized larvae in regulatory development. Optima between 21 and $23{ }^{\circ} \mathrm{C}$ for Coenagrion may even seem maladaptive, since water temperature at $5 \mathrm{~cm}$ depth at a study site for $C$. hastulatum at $58^{\circ} \mathrm{N}$ often exceeded this, with daily peaks occasionally at $30{ }^{\circ} \mathrm{C}$ (Norling, 1976). Findings of constant or falling growth rates just above $20{ }^{\circ} \mathrm{C}$ in later stadia are probably due to a strengthening of the diapause component.

On the other hand, the enigmatic slow growth and steep high-temperature responses of the exclusively northern Coenagrion johanssoni (Wallengren) reported by Nilsson-Örtman, Stoks, De Block \& Johansson (2012) were suggesting extremely high thermal requirements. However, this, and the unexpected performance of this species in different photoperiodic regimes (Śniegula, Nilsson-Örtman \& Johansson, 2012), are consistent with a short-day induced winter diapause in early development, counteracted by high temperatures and seemingly absent in more southern congeners (see also Śniegula, Johansson et al., 2012). All the discussed temperature-diapause interactions will of course also interfere with calculations of temperature sums for development.

\section{Comments on studies of Ischnura elegans}

An impressive series of studies, performed in a most consistent manner under Robby Stoks at the University of Leuven, Belgium, contains additional relevant information on coenagrionid larvae, in particular I. elegans. This work primarily addressed effects of pesticides and factors related to climate warming on development and physiology. A meta-study of control groups in 12 experiments is presented in Supplement 5. With some exceptions, larvae from Denmark and Sweden $\left(55-57^{\circ} \mathrm{N}\right)$ and Southern France $\left(43-45^{\circ} \mathrm{N}\right)$ were reared from eggs under constant conditions, LD 14:10, or sometimes $16: 8$, at 20 and $24{ }^{\circ} \mathrm{C}$. The measured growth rates by weight in early F-0 were always highly variable (regulatory development?), but generally faster for the probably multivoltine southern larvae compared to the northern ones, mostly supposed to be semivoltine (own observations suggest mainly 
univoltine, as in Figure 1b). Southern larvae also accelerated growth at $24{ }^{\circ} \mathrm{C}$ compared to $20{ }^{\circ} \mathrm{C}$. The slower northern larvae instead, with some exceptions, grew still slower at $24^{\circ} \mathrm{C}$.

Data also on F-0 development time was provided by Debecker, Dinh Van \& Stoks (2017), which allowed a simple cross-reference to some own exploratory data, and partly to field observations. At $20{ }^{\circ} \mathrm{C}$, four own northern pre-emergence larvae were as fast as the fastest southern larvae (see Supplement 5 and supporting data from related species in Supplement 3). Thus, at least in some studies the southern larvae may have perceived the rearing conditions as conducive for another immediate generation before winter (pre-emergence development), and comparable to the bivoltines in Figure 1a. However, the slow growth rates (long development times) and negative thermal responses of most northern larvae suggest that these were in regulatory development, somehow preparing to encounter an approaching winter. Different populations of insects are well known to be adapted to the local conditions by different responses to photoperiod (e. g. Danilevsky, 1965; for Odonata see Corbet, 1999, p. 129-130), and it was mentioned as a possible confounder in this experimental approach by Stoks, Geerts \& De Meester (2013) and Verheyen, Tüzün \& Stoks (2019). Identical conditions are thus likely to have produced different programs of development representing different parts of the life cycle. That pre-emergence development at high temperatures is not slow in northern I. elegans larvae is supported by an unexpected small second generation in August in outdoor rearing tanks in southernmost Sweden $\left(55^{\circ} \mathrm{N}\right)$ during the hot summer of 2018 (E. Svensson, personal communication).

However, together these comprehensive studies also demonstrate that the variety of thermal and other responses recorded in I. elegans are part of a complex situation involving many physiological traits, which are traded off against each other (Debecker \& Stoks, 2019; Janssens \& Stoks, 2017; Stoks \& De Block 2011; Stoks \& Córdoba-Aguilar, 2012; Stoks et al., 2008; Stoks et al., 2008; Verheyen et al., 2019; see also references in Supplement 5). The contribution of regulatory responses is just one, but potentially important and so far neglected aspect.

\section{Acclimation and fluctuating temperatures}

The presented thermal responses for regulatory development apply to acclimation after many weeks of constant conditions, whereas own pre-emergence experiments were performed on overwintered specimens, often spending a short time at experimental temperatures, perhaps limiting complete acclimation (Supplement 2). This might have affected the results, but probably not fundamentally (cf. Rohr et al., 2018). Hormonal processes may react slower than enzyme kinetics.

Diel thermoperiod and stochastic temperature changes are normal features in nature and require acclimation, but are also likely to affect the role of temperature and photoperiod as token stimuli for control of diapause phenomena. Diel thermal periodicity is itself a known seasonal cue, interacting with photoperiod, and can also otherwise affect development in many other insects (Beck, 1983; Khelifa, Blankenhorn, Roy, Rohner \& Mahdjoub, 2019; Saunders, 2014). The relative influences of minima, means and maxima, including their phase relationships with the light-dark cycles, are important and are likely to differ between the different response patterns. Despite some elegant recent work on thermoperiod in I. elegans (Verheyen \& Stoks, 2019a and b) the property of thermoperiod as a token stimulus in seasonal regulation has not been addressed and is thus unknown in Odonata.

\section{Conclusions on temperature responses}

The thermal performance of northern and southern populations in dragonflies may not be fundamentally different if the pre-emergence or early phases of the life cycles are compared. The latter seems to apply in the experiments with small libellulid larvae in Suhling, Suhling et al. (2015: Supplement 2 ), producing consistently high optima. The review by Tüzün \& Stoks (2018) indicated that the absence of a shift in thermal performance curves was the most common situation in geographically different populations of insects, followed by a vertical countergradient shift (see also Pritchard et al., 1996 and Verheyen et al., 2019). F-0 post-apolysis development in northern (c. $\left.68^{\circ} \mathrm{N}\right)$ and more southern $\left(58^{\circ} \mathrm{N}\right)$ populations of A. juncea, C. hastulatum and L. dubia in Sweden at least appears to 
be quite uniform between 15 and $20^{\circ} \mathrm{C}$ (mostly unpublished, but see Norling, 1976, 1984b). However, such a basic similarity between latitudes should not be contradictory to findings of different adaptations for performance and survival at extreme temperatures (e.g. Van Dievel, Tüzün \& Stoks, 2019; Verheyen et al., 2018).

The conclusion emerges that the shape of the temperature response curves during active (nondiapause) development could be basically similar in all larval stadia, and that observed differences between sizes (i. e. ontogenetic shifts), situations and populations to a great extent could relate to hormonal control during regulatory development. Responses in seasonal regulation may thus be important components in observed thermal performance and long-term acclimation. There is also a possibility of interactions with other sensory inputs.

\section{Possible prediction in early development: the pre-hibernation cohort split}

The pre-hibernation cohort split is not included in the proposed model. It primarily occurs in some early-flying species, typically with a large WCS. It can start in relatively small sizes, usually in late summer, and produces a gap or frequency minimum at the likely WCS before winter (Figure 1d-f). O. Müller (1996, p. 94) even described a pre-hibernation split in G. vulgatissimus, starting already in spring, at a kind of "second-order WCS". The split is proximately poorly understood and may be heterogeneous, perhaps not always plastic (see Crowley \& Hopper, 2015). The "initial asynchrony" mechanism could sometimes apply, i. e. hatching before or after a critical time. The pre-hibernation and emergence splits could also operate via two "midpoint cueing" critical thresholds in a sequence, and which have evolved to match. The cohorts from a pre-hibernation split can sometimes be experimentally reprogrammed in spring due to the plasticity of the WCS (Norling, 1984a, c).

The fast cohort in a pre-hibernation split displays fast late-season regulatory development, striving to reach above the WCS before winter, preferably with some margin. The slow cohort is more enigmatic, perhaps just routine early development with a safe winter preparation. In the fast cohort larvae have the conflicting needs to both reach above the plastic WCS to shorten development, and accumulate resources for winter survival (cf. Verheyen et al., 2018). In the spring species E. cynosura (Figure 1e), Johnson (1986) found higher winter mortality in univoltines arriving late to F-0 in a fast prehibernation cohort than in semivoltines entering F-0 earlier from an older slow cohort. However, when counted from July of their first year the overall survival of univoltines was higher, which may illustrate this trade-off.

In particular if the WCS is large, a pre-hibernation split is likely to be predictive, starting at a size normally in the predictive range in other species, and where larvae can sense whether emergence is likely after one (fast cohort) or after two more winters (slow cohort). In the latter case the response could show up just as an extremely early and safe winter preparation, manifested by a long critical photoperiod for a winter diapause. Larvae will have plenty of time to grow during the extra year.

There is some experimental evidence for this in L. dubia, where only overwintering F-0 emerge in Sweden and stadia before F-1 are "early" (Norling, 1976, 1984b; cf. Figure 1f). At 58 N, a winter frequency minimum is produced in F-1 by an early winter diapause in F-3 and F-2 already during late summer photoperiods, at the same time as F-1 can continue to moult into F-0 even into September. At $68^{\circ} \mathrm{N}$, the early winter diapause is displaced to F-1 (slow cohort), and the frequency minimum is only present in early interecdysis stages of F- 0 . Apparently, determination of emergence starts below the WCS. A hypothesis of different timing of a partly putative winter diapause in different stadia in different populations of L. dubia and C. hastulatum is illustrated in Norling (1984c, p. 149).

The cohort separation may be assisted by different conditions at different times of hatching, including presence of older larvae and other biotic interactions. This can perhaps be coupled to the often observed decreasing growth ratios and an increase in the total number of stadia in the laterhatching larvae. This is not necessarily leading to a split (Gallesi \& Sacchi, 2019, for Calopteryx splendens (Harris)), but might later be amplified by size-dependent differential responses (Norling, 1984a and c, for C. hastulatum). 
In more asynchronous species, with no pre-hibernation split, genetic or plastic prediction in early development may also exist, apart from simple winter diapauses. Verheyen, et al. (2018) showed strong evidence for early growth differences between populations of the asynchronous Enallagma cyathigerum (Charpentier), correlated with latitude and inferred voltinism under northern commongarden conditions. Perhaps the low reported growth rate in the small northern larvae can be analogous to a slow pre-hibernation semivoltine cohort in Coenagrion, with high priority on a thorough winter preparation and little chance to emerge in the following season. The more southern Enallagma larvae and a univoltine Coenagrion cohort may then be comparable. If the northern Enallagma should hatch early, do they then grow faster? After all, flexibility and plasticity appear to be most prominent properties of these insects. Voltinism is further discussed below.

\section{Life history adjustments to climate and phenology}

As pointed out, within the WCS model almost any phenology and emergence profile can be produced by control of the last overwintering stages, and the rate of pre-emergence development in spring. This can be extended by a later critical time. Latitudinal and phenological patterns in the context of the model, not attempting to separate plasticity and adaptation, are summarized and discussed in Supplement 6. The topics in this section were also addressed in Norling (1984c) on p. $148-153$.

\section{Plasticity as a response to climatic factors}

The plasticity of the WCS alone can contribute to adjust the phenology of a species to latitude/climate. For example, long days combined with low temperatures, both typical for higher latitudes, increases the WCS and works towards a spring species pattern, so adjusting phenology. On the other hand, in a warming scenario, higher temperatures at early-season shorter days will depress the WCS as previously noted (Box 12), or delay the critical time in late-flying summer species (not explicitly tested), which decreases the incidence of regulatory development. These changes contribute to an increase in average voltinism and may allow bivoltinism in some species. The initiation of the cohort split at a smaller size or later in time will tend to preserve or extend the end of the emergence period, and may also contribute to preserve the main start of emergence. With a start of the theoretically high-temperature enhanced regulatory diapauses at a smaller size, overwintering in the most advanced larval stages can be avoided. This reasoning only applies to a summer species pattern at the higher temperatures/lower latitudes, which seems to agree with the phenological data in Johansson et al. (2010).

\section{Box 12. Wood cutting as a field simulation of a warming scenario}

During a 1965 - 1974 study of Aeshna, partly documented in Norling (1984c; cf. Figure 1h), effects of warming were observed when the cool, totally shaded study site at $58^{\circ} \mathrm{N}$ suddenly became exposed to the sun by logging during the winter $1970-71$. This was best documented for $A$. cya$n e a$, the most frequent species. Development suddenly shortened from three, rarely four years, to mostly two. WCS was reduced, so as to allow emergence to be preceded by three overwintering stadia instead of two. The last winter, which was previously most often spent in F-0, spring species fashion (dominant in 5 winters out of 7), changed to a dispersed summer species stadium distribution where only three-year specimens overwintered in F-0. However, thanks to seasonal regulation, phenology did not seem to be drastically affected, although emergence started earlier. Due to increasing population density under the new conditions, average growth rate and voltinism were subsequently somewhat reduced.

In a northern expansion, plasticity in the WCS can be supplemented by a plastic accelerating effect of high latitude long days on pre-emergence development. The latter effect was proposed by Corbet 
(2003) to explain observations of a similar start of emergence at both high and low latitudes in some species (see also Johansson et al., 2010). However, as suggested above, it seems more likely that plastic and/or adaptive differences in WCS and the last overwintering stages are dominant explanations to such observations. Conversely, during regulatory development the effect of high-latitude long summer days should delay rather than accelerate, as demonstrated by Sniegula, Johansson et al. (2012) when testing Corbet's proposal. This can theoretically decrease the size during the last winter. However, lower temperatures may compensate, perhaps even overcompensate, by lowering the diapause intensities.

In a warming scenario, the lower time stress from the shorter days of an early warm spring will not only affect the cohort split as mentioned above, but also induce a slower pre-emergence development, which could partly offset the effects of an earlier start of development (Norling, 1971; Figure 6; Supplement 3). However, these experiments were performed at a constant spring photoperiod of LD 16:8 (late April with Civil Twilights), without the normal subsequent increase in photoperiod.

\section{Genetical adaptation to climate}

As mentioned earlier, there are genetical intraspecific adaptations to latitude in the WCS and also in critical photoperiods, which both increase with latitude (e.g. Corbet, 1999; Norling, 1984c), although maternal effects were not examined. Intrinsically weaker regulatory diapause intensities at higher latitudes are another likely adaptation, enabling larvae to reach an appropriate last overwintering stage when summers are shortening (Norling, 1984c). Such high-latitude adaptations of regulatory diapause during early F-0 intrastadium substages are present in L. dubia, (Norling, 1984b), and more generally in C. hastulatum (Norling, 1984a). Differences in regulatory development of this kind were also shown between urban and rural populations of $C$. puella, the former adapted to a warmer environment (Tüzün, Op de Beeck, Bran, Janssens \& Stoks, 2017). However, the situation may be different if the critical time is late and bivoltinism possible, and regulatory development starts late in the season (Stoks et al., 2013).

As in plasticity, another possible but yet unproven high-latitude adaptation is an intrinsically faster pre-emergence development, which could be assumed to be more time constrained due to the shorter season. Both of these adaptations are concordant with the compensation for a shorter season by faster development as seen in countergradient variation (Conover \& Schulz, 1995), but here limited to the predictive range.

\section{Voltinism}

As well known, a transition to higher latitudes is stepwise compensated by decreased voltinism (Corbet et al., 2006). Thus, one generation takes increasingly longer time, sometimes many years. It is often implicitly assumed that transition zones with mixed voltinism are narrow (e.g. Verheyen et al., 2018), but as pointed out, mixed voltinism is probably quite universal, but underreported. Local and temporal differences in many factors will contribute to variable growth rates and voltinism in an area, e.g. differences in habitats, weather, and shading, all affecting temperature, and biotic factors, such as food, predators, competition and population density. These factors can affect voltinism by affecting growth, either directly or indirectly, e. g. via changes in behaviour and access to food (Banks \& Thompson, 1987; Braune, Richter, Söndgerath \& Suhling, 2008; Johnson, Martin, Mahato, Crowder \& Crowley, 1995; Macan, 1974; Martin, Johnson \& Moore, 1991). At least temperature can also act as an environmental cue and affect voltinism via seasonal regulation. Note that the increased voltinism in a warming scenario will stop at univoltinism in phenologically restricted species, e.g. those with a spring species pattern.

Provided there is no synchronizing stage, such as the obligatory egg diapause in most Aeshna (Figure $1 \mathrm{~g}, \mathrm{~h}$ ), and to some extent F-0 in spring species (Figure 1e, f), there is likely to be some alternating voltinism (Figure 1b-d), also promoting gradual shifts in average voltinism. In these examples the first emergers are semivoltine, and their offspring are prime candidates for a univoltine development, and the reverse. This produces a fluctuating or oscillating time constraint and so an 
oscillating pressure on seasonal regulation between generations, as also discussed by Corbet (1999, p. $233-234)$ and Norling (1984c, p. 150 and figure 15 therein). In this connection, see also the mathematical model in Gurney, Crowley \& Nisbet (1992) and discussions in Nygren, Bergström \& Nylin (2008) and Shama, Campero-Paz, Wegner, De Block \& Stoks (2011). Since a cohort split is separating extremes of time constraint and time surplus, a population with mixed voltinism must simultaneously contain these extremes within the predictive range.

Also differences in latitudinal adaptation to voltinism during early development might exist, as indicated by Verheyen et al. (2018) and touched upon earlier. There is also the possibility that mixed voltinism can be a strategy in itself in some species, e. g. risk spreading between years (Danks, 2006; cf. Crowley \& Hopper, 2015).

\section{Connections to lower latitudes and other types of life history}

Extending the reasoning on latitudinal patterns in Supplement 6 to permanent waters at a hypothetical interface between tropical/subtropical and temperate areas we may have the following situation: winter is becoming unsuitable for adults, but larvae can grow or survive in quiescence. A late-stadium regulatory development can then be hypothesized to control the timing of emergence, with a late critical time, and the environmental cues for initiating a cohort split could consist of decreasing days, perhaps in conjunction with cooler temperatures, reminding of Cloeon dipterum (Funk et al., 2019).

In hot and seasonally dry areas such as the Mediterranean an adult pre-reproductive summer diapause is a particularly important means of regulation and provides survival of temporary drought at the same time as the wet autumn - winter months often can be used for larval growth (Corbet, 1999; Samraoui \& Corbet, 2000; Suhling, Sahlén et al., 2015). Winter growth can even be necessary because the habitats may dry out as early as April. Larvae may not need to be regulated since the adult diapause would tend to lock them in univoltinism. Orthetrum cancellatum (Linnaeus) has an approximate latitudinal distribution between North Africa and central Sweden (Dijkstra \& Lewington, 2006), and southern populations may develop in this way at the same time as it seems to be a typical flexible summer species with diapausing larvae in Central Europe (Flenner et al., 2010). In the south some populations in permanent waters may also be both uni- and bivoltine (Flenner et al., 2010; Hadjoudj et al., 2014).

The partly migratory Anax junius is well studied in North America (e.g. Hallworth, Marra, McFarland, Zahendra \& Studds, 2018; May, Gregoire, Gregoire, Lubertazzi \& Matthews, 2017; May \& Matthews, 2008; Thompson, 2019; Trottier, 1971; see also Corbet, 1999, p. 244, $414-417$ and references therein) and ranges from tropical Central America to southern Canada. In the south, emergence can take place throughout the year. In the north mature adults can arrive in spring from lower latitudes, and their offspring are leaving south in the autumn for another generation. At the same time a resident population can overwinter as larvae in middle to large sizes, evidently in true quiescence even during the cold winters in Minnesota at $45^{\circ} N$ (Thompson, 2019; see also above). The residents emerge during early summer, not always separated from migrants. Remarkably, it appears that even metamorphosing (post-apolysis) F-0 laggards might survive winter to emerge extremely early in spring (see Corbet, 1999, p. 244). An often-observed absence of residents in the north could be related to poor winter survival, partly mediated by the lack of diapause (Thompson, 2019, p. 37-38). Own larval sampling at the Calgary University pond in Canada $\left(51^{\circ} \mathrm{N}\right)$ July to September 1990 revealed no residents despite a big population of migrants.

Thus, a winter diapause does not seem to be associated with seasonal regulation in this species. The rather narrow split between migrant and resident cohorts during late summer (Thompson, 2019, p. 49) strongly reminds of the bivoltine emergence cohort split in Figure 1a, and seems to include regulatory development also affecting thermal responses (cf. May \& Matthews, 2008; Trottier, 1971). The narrowness of the split in A. junius is logical as the migrants can emerge late because they leave to reproduce further south.

The present account also excludes obligatory univoltine dragonflies overwintering as eggs (e.g. most Lestes, most Sympetrum, and Aeshna mixta Latreille) (Corbet, 1999, p. 224). The egg diapause serves to limit hatching to the spring, and an additional pre-reproductive diapause in the adult, often present at lower latitudes, can displace reproduction to late summer (Corbet, 1999; Jödicke, 1997; 
Ueda, 1978, 1989). Larval development may be regarded as an obligatory, genetically fixed early to pre-emergence development throughout larval life, since there is no alternative, and larvae develop like a second generation in other life-cycle types. Accelerating effects of time constraints, present during shorter summers, are well studied (e.g. Stoks et al., 2008). Little is known if both early and pre-emergence phases can be distinguished, although it might be the case in Lestes sponsa (Norling, 2018). Larvae of these species never prepare for winter, but Aeshna cyanea (Müller), also with an obligatory egg diapause, can display an emergence cohort split between this type of univoltinism and larval-overwintering semivoltinism (Jödicke, 1999; Robert, 1959, p. 192; Schaller, 1960, p. 780). Otherwise A. cyanea follows the WCS model with a 2-4-year development (Norling, 1971, 1984c; Box 12).

\section{Reflections on physiology and behaviour}

As pointed out above, unrecognized diapause phenomena in different response patterns may have been present in some earlier studies, at least affecting growth responses to photoperiod and temperature. We probably have effects correlated with the response patterns also on a range of other aspects of performance. This may be an example of the correlated traits in development, physiology and behaviour as described in the pace-of-life syndrome, "POLS" (Réale et al., 2010), but here applied to alternative or successive pathways in the development of an individual. POLS was actually mentioned in the connection of cohort splitting and development rates by Khelifa, Zebsa, Amari, Khalil Mellal, \& Mahdjoub (2019).

In physiology we may have effects of the response patterns related to food assimilation, starvation, heat and cold resistance, and sensitivity to harmful substances. Otherwise we may have differences in lifestyle and general activity levels, foraging, cannibalism, competitive and antipredator behaviour, and preferences of microhabitat and temperature. Behavioural changes associated with diapause, such as reduced feeding and activity, are well-known in many insects (Danks 1987, p. 34, 43; Tauber et al., 1986, p. 81). Also, different levels of time stress in larvae of non-diapausing odonate species can be important in this context (Śniegula, Gołab \& Johansson, 2017; Stoks et al., 2008), but diapause is likely to have a still more pronounced effect. Reduced feeding during diapause agrees with own observations in experiments, although not quantified. However, Corbet (1999, p. 109) and Ingram (1975) reported no reduction of feeding in diapausing Odonata.

The pace-of-life syndrome has recently been the subject of studies on latitudinal population differences in I. elegans (Debecker \& Stoks, 2019), and differences across species in the genus (Debecker, Sanmartín-Villar, de Guinea-Luengo, Cordero-Rivera \& Stoks, 2016). From the meta-study in Supplement 5 (experiment c), it seems possible, and even likely, that the reported intraspecific latitudinal differences are actually relevant for different response patterns and different phases of the life cycle, southern larvae more often preparing for reproduction and northern ones for an elusive winter. Thus, in these pace-of-life studies it appears that response pattern could be the main driver of the syndrome. Larvae preparing for reproduction and larvae preparing for winter must have very different priorities, and both situations are relevant for both latitudes. Northern pre-emergence larvae could rather be more time constrained in late stadia and not be expected to grow slower than southern ones.

These questions become more tangible if we look at the development of C. puella, another common model species, as seen in the field at $58^{\circ} \mathrm{N}$ (Figure 1c). Here, larvae of c. $2.5 \mathrm{~mm}$ head width (F2 and F-1) are found in late May - early June as time constrained pre-emergence univoltine larvae, and in August - September as slow-growing time surplus regulatory larvae of the semivoltine cohort. They do have different growth responses to photoperiod and temperature (Figure 6) and based on simple reasoning some further predictions can be made in line with the pace-of-life syndrome, also partly supported by observations.

The time constrained early summer group should gain from active foraging in shallow warm water, and the latter was actually indicated when taking the field samples. They certainly show a costly high metabolism, and probably suffer from increased predation and trade time for smaller size, emerging as smaller, less fit adults (cf. decreasing size of F-0 during emergence in Figure 1c; Stoks et al., 2008). The slow larvae are forced to add an extra year to development, and we could expect an increased emphasis on maintenance and long-term survival. They have ample time to adjust growth 
and morphogenesis to optimize the size and stadium for the last winter, so preparing for both an optimum adult size and emergence time. Most of them are actually overwintering as big F-1. They could generally thrive under sheltered but suboptimal conditions in places with a lower temperature and fewer prey encounters and adopt a passive sit and wait strategy with less predation losses.

How can this be examined in a controlled manner? Rearing larvae from eggs in a constant photoperiod is evidently trapping larvae in regulatory diapause in later stadia, which is one part of such a study. Another common, but potentially more versatile approach is a roughly natural photoperiodic and thermal regime (e.g. Śniegula, Johansson et al., 2012). Important aspects for the outcome are successive winter preparations, the size during winter, a winter treatment of sufficient duration for a natural spring development, and the spring conditions themselves. Suitably modified and manipulated, this approach can be used to examine both different levels of time constrained pre-emergence development, and time surplus regulatory development, even among siblings.

\section{Conclusions, implications and suggestions for experimental work on temperate zone species}

The response patterns in seasonal regulation seem to have a high and perhaps underrated proximate explanatory power, but need to be further explored in a wider perspective of adaptations, interactions and trade-offs in larval biology than presented here. The proposed model, although consistent and fitting field observations, is to some extent based on circumstantial evidence from a limited material and so in need of further confirmation. The model implies that the rates of growth and development at a particular time can, apart from direct effects of temperature and food, be largely controlled by interactions between larval size, photoperiod, temperature and previous conditions, acting on the diapause component. Also factors such as the presence of competitors and predators could possibly be added to this complex.

The variety of responses in seasonal regulation provides precision and flexibility to cope with variable conditions (cf. Danks, 1987, p. 226, table 40 on p. 229), but the complexity has clear implications for experimental work. How solve the problems of long-term constant conditions, and those of differential responses in common-garden comparisons? Mimicking naturally progressing photoperiods and temperature is complicated, and sensitive to time and size differences between treatment groups, which then may not be fully comparable. Within the framework of the model, there are a couple of simpler solutions, which, however, would need some exploratory testing.

One is to use larvae in early development, which should be either unresponsive to photoperiod, or sometimes only responsive to short days. Experiments in constant summer photoperiods, relevant for the most northern populations, may work up to a size close to the predictive range. This would be most useful in spring species. For example, L. dubia in Sweden show no traces of regulatory longday diapauses until weakly in F-1. However, caution should be observed when approaching the critical size, in particular in summer species. High-temperature performance in the work of Tüzün et al. (2017) seems to indicate a successive transition to regulatory development in C. puella, starting at relatively small sizes, and photoperiodic responses in the northern $C$. hastulatum suggest the same (Norling, 1984a).

In pre-emergence development, a study can be performed with a uniform, high time constraint, which is relatively simple in summer species. A slowly initiated photoperiodic and thermal winter treatment above a likely WCS for a couple of months can be followed by constant latitude-relevant summer photoperiods, or by one relevant for high-latitude larvae only. The pre-emergence response to a native summer photoperiod and to a longer one may not be different, but it needs to be tested.

Regulatory development is important in latitudinal and phenological adaptation, but more difficult to examine in population comparisons. Together, problems can arise from differences in critical photoperiod, from a probable effect of seasonal changes and from the graded responses with variable and size-dependent diapause components.

The points below highlight important issues and implications of the model. 
1. The larval stage is usually not one homogeneous unit. Just recording the time from hatching to emergence might conceal important information, e.g. ontogenetic variation and maximum possible growth rates.

2. The different response patterns represent different phases of the life cycle with different predictions of emergence and they display different, partly opposite effects of photoperiod and temperature on growth, and most likely also affect other physiological parameters and behaviour. The latter aspects are poorly known, and it must be recommended to consider the described response patterns also in such studies.

3. If the response patterns in an experiment are not known, it is uncertain what part of the life cycle and growth season the results are relevant for. If larvae are bound for reproduction or overwintering can have a profound effect on the outcome.

4. Populations from different latitudes under common-garden conditions most likely show responses relevant for at least slightly different situations or parts of the life cycle, displaying at least different levels of time stress, sometimes entirely different response patterns.

5. Communicating larval size or stadia in experimental studies can be crucial. Responses normally change with size, and a comparison of treatment groups where sizes are different may be confounded.

6. Changes in photoperiod and temperature are important for normal development and the correct timing of seasonal events.

7. Long-term constant conditions often tend to induce a permanent regulatory development with diapauses in later stadia, which start to prepare for a winter never coming. Without the natural reset to pre-emergence responses they will emerge with a variable delay. However, pre-emergence development may be possible for bi- or multivoltine populations, and in short days an additional dedicated winter diapause may occur already during early development in northern species.

8. Winter is a key event in temperate areas. It is resetting responses and terminating diapause, and the size during winter can be crucial for later development. An experimental winter simulation should take its time to yield natural responses to spring conditions.

\section{Acknowledgments}

I want to acknowledge the contributions of a few persons, some no longer with us, who have been of crucial importance for leading me into this field of odonatology and make me remain there. First, the late Philip Corbet, whose early writings raised my curiosity on life histories and seasonal regulation, and who also provided much encouragement thereafter. The late Gordon Pritchard, Canada, invited me to Calgary and stimulated and supported my work at a critical time, when also Ken Deacon, Canada, provided much stimulation. I also wish to thank Philip Crowley, Frank Johansson and Szymon Śniegula for encouragement, useful information and comments on different versions of the manuscript, and, in particular, Frank Suhling, whose early and late proposals greatly improved the final result. A discussion with Mike Parr was also most helpful. Finally, two anonymous reviewers and the editors provided most helpful suggestions.

\section{References}

Angilletta, M., J., Jr (2009). Thermal adaptation. A theoretical and empirical synthesis. Oxford, UK: Oxford University Press. https://doi.org/10.1093/acprof:oso/9780198570875001.1

Aoki, T. (1999). Larval development, emergence and seasonal regulation in Asiagomphus pryeri (Selys) (Odonata: Gomphidae). Hydrobiologia, 394, 179 - 192. https://doi.org/10.1023/A:1003626011 117

Banks, M. J., \& Thompson, D. J. (1987). Regulation of damselfly populations: the effects of larval density on larval survival, development rate and size in the field. Freshwater Biology, 17, 357-365. https://doi.org/10.1111/j. 1365 - 2427.1987.tb01 055.x

Beck, S. D. (1983). Insect thermoperiodism. Annual Review of Entomology, 28, 91-108. https://doi.org/10.1146/ annurev.en.28.010 183.000515 
Braune, E., Richter, O., Söndgerath, D., \& Suhling, F. (2008). Voltinism flexibility of a riverine dragonfly along thermal gradients. Global Change Biology, 14, 470 - 482. https://doi.org/10.1111/j.1365 - 2486.2007.01 525.x

Clarke, A. (2003). Costs and consequences of evolutionary temperature adaptation. Trends in Ecology and Evolution, 18, 573 - 581. https://doi.org/10.1016/j.tree.2003.08007

Conover, D. O., \& Schulz, E. T. (1995). Phenotypic similarity and the evolutionary significance of countergradient variation. Trends in Ecology and Evolution, 10, 248 - 252. https://doi.org/10.1016/S0169 - 5347(00)89081-3

Corbet, P. S. (1954). Seasonal regulation in British dragonflies. Nature, 174, 655, 777. https://doi.org/10.1038/ $174655 \mathrm{a} 0$

Corbet, P. S. (1955). A critical response to changing length of day in an insect. Nature, 175, 338 - 339. https://doi.org/ $10.1038 / 175338 \mathrm{~b} 0$

Corbet, P. S. (1956a). The life-histories of Lestes sponsa (Hansemann) and Sympetrum striolatum (Charp.) (Odonata). Tijdschrift voor Entomologie, 99, 217-229.

Corbet, P. S. (1956b). Environmental factors influencing the induction and termination of diapause in the emperor dragonfly, Anax imperator Leach (Odonata: Aeshnidae). Journal of Experimental Biology, 33, 1 - 14.

Corbet, P. S. (1957a). The life-histories of two spring species of dragonfly (Odonata: Zygoptera). Entomologist's Gazette, 8, 79-89.

Corbet, P. S. (1957b). The life-histories of two summer species of dragonfly (Odonata: Coenagriidae). Proceedings of the Zoological Society of London, 128, 403 - 418. https://doi.org/10.1111/j.1096 - 3642.1957.tb00334.x

Corbet, P. S. (1957c). The life-history of the Emperor Dragonfly, Anax imperator Leach (Odonata: Aeshnidae). Journal of Animal Ecology, 26, 1-69. https://doi.org/10.2307/1781

Corbet, P. S. (1960). Seasonal regulation. In: Corbet, P. S., C. Longfield \& N.W. Moore "Dragonflies" (pp. $138-$ 148). London: Collins

Corbet, P. S. (1962). A biology of dragonflies. London: Witherby.

Corbet, P. S. (1999). Dragonflies: behaviour and ecology of Odonata. Colchester: Harley Books.

Corbet, P. S. (2002). Stadia and growth ratios of Odonata: a review. International Journal of Odonatology, 5, 45 - 73. https://doi.org/10.1080/13887890.2002.9748 176

Corbet, P. S. (2003). A positive correlation between photoperiod and development rate in summer species of Odonata could help to make emergence date appropriate to latitude: a testable hypothesis. Journal of the Entomological Society of British Columbia, 100, 3 - 17.

Corbet, P. S., \& Corbet, S. A. (1958). Emergence of a summer species of dragonfly. Nature, 182, 194. https://doi.org/ $10.1038 / 182194 \mathrm{a} 0$

Corbet, P. S., \& Harvey I. F. (1989). Seasonal regulation in Pyrrhosoma nymphula (Sulzer) (Zygoptera: Coenagrionidae). 1. Seasonal development in nature. Odonatologica, 18, $133-145$.

Corbet, P. S., \& Harvey I. F., Abisgold, J., \& Morris, F. (1989). Seasonal regulation in Pyrrhosoma nymphula (Sulzer) (Zygoptera: Coenagrionidae). 2. Effect of photoperiod on larval development in spring and summer. Odonatologica, 18, 333-348.

Corbet, P. S., Suhling, F. \& Soendgerath, D. (2006). Voltinism of Odonata: a review. International Journal of Odonatology, 9, 1-44. https://doi.org/10.1080/13887890.2006.9748261

Crowley, P. H., \& Hopper, K. R. (2015). Mechanisms for adaptive cohort splitting. Ecological Modelling, 308, 1- 13. https://doi.org/10.1016/j.ecolmodel.2015.03018

Danilevsky, A. S. (1965). Photoperiodism and seasonal development of insects (Russian edition 1961). Edinburgh and London: Oliver \& Boyd.

Danks, H.V. (1987). Insect Dormancy: An Ecological Perspective. Ottawa: Biological Survey of Canada (Terrestrial Arthropods).

Danks, H.V. (2002). The range of insect dormancy responses. European Journal of Entomology, 99, 127-142. https://doi.org/10.14411/eje.2002 021

Danks, H. V. (2006). Key themes in the study of seasonal adaptations in insects II. Life cycle patterns. Applied Entomology and Zoology, 41, 1-13. https://doi.org/10.1303/aez.2006.1

Deacon, K. J. (1975). The seasonal regulation of Leucorrhinia intacta Hagen (Odonata: Libellulidae). (Unpublished master's thesis). University of Waterloo, Ontario, Canada.

Deacon, K. J. (1979). The seasonality of four Odonata species from mid Canterbury, South Island, New Zealand. (Unpublished doctoral dissertation). University of. Canterbury, New Zealand. Retrieved from http://hdl.handle. net/10092/6958, http://dx.doi.org/10.26021/7122

Debecker, S., Dinh Van, K., \& Stoks, R. (2017). Strong delayed interactive effects of metal exposure and warming: latitude-dependent synergisms persist across metamorphosis. Environmental Science and Technology, 51, 24092417. https://doi.org/10.1021/acs.est.6b04989

Debecker, S., Sanmartín-Villar, I., de Guinea-Luengo, M., Cordero-Rivera, A., \& Stoks, R. (2016). Intergrating the pace-of-life syndrome across species, sexes and individuals: covariation of life history and personsality under pesticide exposure. Journal of Animal Ecology, 85, 726 - 738. https://doi.org/10.1111/1365 - 2656.12499

Debecker, S., \& Stoks, R. (2019). Pace of life syndrome under warming and pollution: integrating life history, behaviour, and physiology across latitudes. Ecological Monographs, 89, e01332. 10.1002/ecm.1332. https://doi. org/10.1002/ecm.1332 
De Block, M., Slos, S., Johansson, F., \& Stoks, R. (2008). Integrating life history and physiology to understand latitudinal size variation in a damselfly. Ecography, 31, 115-123. https://doi.org/10.1111/j.2007.0906-7590.05 313.x

Dell, A. I., Pawar, S., \& Savage, V. M. (2011). Systematic variation in the temperature dependence of physiological and ecological traits. Proceedings of the National Academy of Sciences, 108, 10591-10596. https://doi.org/10. 1073/pnas.1015178 108

Denlinger, D. L., Yocum, G. D., \& Rinehart, J. P. (2012). Chapter 10 - Hormonal Control of Diapause. In Gilbert, L. I. (Ed), Insect Endocrinology (pp. 430 - 463). San Diego: Academic Press. https://doi.org/10.1016/B978-0-12384749-2.10010-X

Di Giovanni, M. V., Goretti, E., La Porta, G., \& Ceccagnoli, D. (2000). Larval development of Libellula depressa (Odonata, Libellulidae) from pools in central Italy. Italian Journal of Zoology, 67, 343 - 347. https://doi.org/10. 1080/11250000009356337

Dijkstra, K. D., \& Lewington, R. (2006). Field guide to the dragonflies of Britain and Europe. Gillingham: British Wildlife Publishing.

Dmitriew, C. M. (2011). The evolution of growth trajectories: What limits growth rate. Biological Reviews, 86, 97116. https://doi.org/10.1111/j.1469 - 185X.2010.00 136.x

Eller, J. G., 1963. Seasonal regulation in Pachydiplax longipennis (Burmeister) (Odonata: Libellulidae). (according to T\&F rules) (Unpublished doctoral dissertation). University of North Carolina, Chapel Hill.

Ferreras-Romero, M. (1997). The life history of Boyeria irene (Fonscolombe, 1838) (Odonata: Aeshnidae) in Sierra Morena Mountains (southern Spain). Hydrobiologia, 345, 109-116. https://doi.org/10.1023/A:1002967220090

Flenner, I., Richter, O., \& Suhling, F. (2010). Rising temperature and development in dragonfly populations at different latitudes. Freshwater Biology, 55, 397-410. https://doi.org/10.1111/j.1365-2427.2009.02289.x

Fliedner, T., \& Fliedner, H. (2000). Herbstschlupf von Gomphus vulgatissimus (Odonata: Gomphidae) [Autumn emergence of Gomphus vulgatissimus (Odonata: Gomphidae)]. Libellula, 19, $79-89$.

Funk, D. H., Sweeney, B. W., \& Jackson, J. K. (2019). Why some mayfly adults are older and larger: Photoperiodic induction of larval quiescence. Freshwater Science, 38, 725 - 741. https://doi.org/10.1086/705749

Furunishi, S., \& Masaki, S. (1983). Photoperiodic control of development in the ant-lion Hagenomyia micans (Neuroptera: Myrmeleontidae). Entomologia Generalis 9, 51 - 62. https://doi.org/10.1127/entom.gen/9/1983/51

Gallesi, M. M., \& Sacchi, R. (2019). Voltinism and larval population structure of Calopteryx splendens (Odonata: Calopterygidae) in the Po Valley. International Journal of Odonatology, 22, 21-30. https://doi.org/10.1080/ 13887890.2018 .1563916

Gotthard, K., Nylin, S., \& Wiklund, C. (2000). Individual state controls temperature dependence in a butterfly (Lasiommata maera). Proceedings of the Royal Society of. London, 267, 589-593. https://doi.org/10.1098/rspb. 2000.1042

Gurney, W. S. C., Crowley, P. H., \& Nisbet, R. M. (1992). Locking life-cycles onto seasons: Circle-map models of population dynamics and local adaptation. Journal of Mathematical Biology, 30, 251-279. https://doi.org/10. 1007/BF00176151

Hadjoudj, S., Khelifa, R., Guebailia, A., Amari, H., Hadjadji, S., Zebsa, R., Houhmadi, M., \& Moulaï, R. (2014). Emergence ecology of Orthetrum cancellatum: temporal pattern and microhabitat selection (Odonata: Libellulidae). Annales de la Société entomologique de France (N.S.): International Journal of Entomology, 50, 343 - 349. https://doi.org/10.1080/00379271.2014.938941

Hallworth, M. T., Marra, P. P., McFarland, K. P., Zahendra, S. \& Studds, C.E. (2018). Tracking dragons: stable isotopes reveal the annual cycle of a long-distance migratory insect. Biol. Lett. 14, 20180741. https://dx.doi.org/ $10.1098 / \mathrm{rsbl} .2018 .0741$

Hodek, I. (2002). Controversial aspects of diapause development. European Journal of Entomology, 99, 163 - 173. https://doi.org/10.14411/eje.2002 024

Hodek, I., \& Hodková, M. (1988). Multiple role of temperature during insect diapause: A review. Entomologia experimentalis et applicata, 49, 153 - 165. https://doi.org/10.1111/j.1570 - 7458.1988.tb02 486.x

Ingram, B.R. (1971). The seasonal ecology of two species of damselflies (Odonata: Zygoptera) with special reference to the effects of photoperiod and temperature on nymphal development (Unpublished doctoral dissertation). University of North Carolina, Chapel Hill.

Ingram, B.R. (1975). Diapause termination in two species of damselflies. Journal of Insect Physiology, 21, 1909 1016. https://doi.org/10.1016/0022 - 1910(75)90222-X

Ingram, B.R., \& Jenner, C.E. (1976a). Influence of photoperiod and temperature on developmental time and number of moults in nymphs of two species of Odonata. Canadian journal of Zoology, 54, 2033 - 2045. https://doi.org/ $10.1139 / \mathrm{z} 76-237$

Ingram, B.R., \& Jenner, C.E. (1976b). Life histories of Enallagma hageni (Walsh) and E. aspersum (Hagen) (Zygoptera: Coenagrionidae). Odonatologica, 5, 331-345.

Janssens, L., \& Stoks, R. (2017). Chlorpyrifos-induced oxidative damage is reduced under warming and predation risk: Explaining antagonistic interactions with a pesticide. Environmental Pollution, 226, 79-88. https://doi.org/ 10.1016/j.envpol.2017.04012

Johansson, F., \& Norling, U. (1994). A five year study of the larval life history of Coenagrion hastulatum (Charpentier) and C. armatum (Charpentier) in northern Sweden (Zygoptera: Coenagrionidae). Odonatologica, 23, $355-$ 364. 
Johansson, F., Śniegula, S., \& Brodin, T. (2010). Emergence patterns and latitudinal adaptations in development time of Odonata in North Sweden and Poland. Odonatologica, 39, 97- 106.

Johnson, D. M. (1986). The life history of Tetragoneuria cynosura (Say) in Bays Mountain Lake, Tennessee, United States (Anisoptera: Corduliidae). Odonatologica, 15, 81-90.

Johnson, D. M., Martin, T. H., Mahato, M., Crowder, L. B., \& Crowley, P. H. (1995). Predation, density dependence, and life histories of dragonflies: a field experiment in a freshwater community. Journal of the North American Benthological Society, 14, 547-562. https://doi.org/10.2307/1467540

Jödicke, R. (1997). Die Binsenjungfern und Winterlibellen Europas: Lestidae [The spreadwings and winter damsels of Europe: Lestidae]. Magdeburg: Westarp Wissenschaften.

Jödicke, R. (1999). Nachweis einjähriger Entwicklung bei Aeshna cyanea (Müller) (Anisoptera: Aeshnidae) [Evidence of univoltine development in Aeshna cyanea (Müller) (Anisoptera: Aeshnidae)]. Libellula, 18, 169-174.

Khelifa, R., Blanckenhorn, W. U., Roy, J., Rohner, P. T., \& Mahdjoub, H. (2019). Usefulness and limitations of thermal performance curves in predicting ectotherm development under climatic variability. Journal of Animal Ecology 88, 1901 - 1912. https://doi.org/10.1111/1365-2656.13077

Khelifa, R., Zebsa, R., Amari, H., Khalil Mellal, M., \& Mahdjoub, H. (2019). Field estimates of fitness costs of the pace-of-life in an endangered damselfly. Journal of Evolutionary Biology 32, 943 - 954. https://doi.org/10.1111/ jeb.13493

Koch, K. (2015). Influence of temperature and photoperiod on embryonic development in the dragonfly Sympetrum striolatum (Odonata: Libellulidae). Physiological Entomology, 40, 90 - 101. https://doi.org/10.1111/phen.12091

Koštál, V. (2006). Eco-physiological phases of insect diapause. Journal of Insect Physiology, 52, 113 - 127. https:// doi.org/10.1016/j.jinsphys.2005.09008

Kutcherov, D. A., Lopatina, E. B., \& Kipyatkov, V. E. (2011). Photoperiod modifies thermal reaction norms for growth and development in the red poplar leaf beetle Chrysomela populi (Coleoptera: Chrysomelidae). Journal of Insect Physiology, 57, $892-898$. https://doi.org/10.1016/j.jinsphys.2011.03028

Lopatina, E. B., Kipyatkov, V. E., Balashov, S. V., \& Kutcherov, D. A. (2011). Photoperiod-temperature interaction-a new form of seasonal control of growth and development in insects and in particular a Carabid Beetle, Amara communis (Coleoptera: Carabidae). Journal of Evolutionary Biochemistry and Physiology, 47, 578 - 592. https:// doi.org/10.1134/S002209301106010X

Lutz, P. E. (1968a). Life-history studies on Lestes eurinus Say (Odonata). Ecology, 49, 576 - 579. https://doi.org/10. $2307 / 1934132$

Lutz, P. E. (1968b). Effects of temperature and photoperiod on larval development in Lestes eurinus Say (Odonata: Lestidae). Ecology, 49, 637-644. https://doi.org/10.2307/1935529

Lutz, P. E. (1974a). Effects of temperature and photoperiod on larval development in Tetragoneuria cynosura (Odonata: Libellulidae). Ecology, 55, 370 - 377. https://doi.org/10.2307/1935224

Lutz, P. E. (1974b). Environmental factors controlling duration of larval instars in Tetragoneuria cynosura (Odonata: Libellulidae). Ecology, 55, 630 - 637. https://doi.org/10.2307/1935 153

Macan, T. T. (1974). Twenty generations of Pyrrhosoma nymphula (Sulzer) and Enallagma cyathigerum (Charpentier) (Zygoptera: Coenagrionidae). Odonatologica, 3, 107-119.

Mansingh, A. (1971). Physiological classification of dormancies in insects. Canadian Entomologist, 103, 983 - 1009. https://doi.org/10.4039/Ent103 983-7

Martin, T. H., Johnson, D. M., \& Moore, R. D. (1991). Fish-mediated alternative life-history strategies in the dragonfly Epitheca cynosura. Journal of the North American Benthological Society, 10, 271-279. https://doi.org/10. $2307 / 1467600$

Masaki, S. (1980). Summer diapause. Annual Review of Entomology, 25, 1-25. https://doi.org/10.1146/annurev.en. 25.010180 .000245

May, M. L., Gregoire, J. A., Gregoire, S. M., Lubertazzi, M. A., \& Matthews, J.H. (2017). Emergence phenology, uncertainty, and the evolution of migratory behavior in Anax junius (Odonata: Aeshnidae). PLoS One 12, e0183 508. https://doi.org/10.1371/journal.pone.0183508

May, M. L., \& Matthews, J. H. (2008). Migration in Odonata: An overview with special focus on Anax junius. In A. Cordoba-Aguilar (Ed), Dragonflies: Model Organisms for Ecological and Evolutionary Research (pp. 63 - 77). Oxford: Oxford University Press. https://doi.org/10.1093/acprof:oso/9780199230693003.0006

Mikolajewski, D. J., De Block, M., \& Stoks, R. (2015). The interplay of adult and larval time constraints shapes species differences in larval life history. Ecology, 96, 1128 - 1138. https://doi.org/10.1890/14-0262.1

Miyazaki Y., Nisimura T., \& Numata H. (2014). Circannual rhythms in insects. In: Numata H., Helm B. (eds) Annual, Lunar, and Tidal Clocks, pp. 333 - 350. Tokyo: Springer. https://doi.org/10.1007/978-4-431-55261-1 16

Müller, H. J. (1970). Formen der Dormanz bei Insekten [Forms of dormancy in insects]. Nova Acta Leopoldina N. F., 35, 7-27. https://doi.org/10.1007/BF02040933

Müller, H. J. (1992). Dormanz bei Arthropoden [Dormancy in arthropods]. Jena-Stuttgart- New York: Gustav Fischer Verlag.

Müller, O. (1995). Ökologische Untersuchungen an Gomphiden (Odonata: Anisoptera) unter besonderer Berücksichtigung ihrer Larvenstadien [Ecological studies on gomphids (Odonata: Anisoptera) with particular consideration of their larval stages]. (Doctoral dissertation). Humboldt-Universität Berlin. Göttingen: Cuvillier Verlag. 
Nilsson-Örtman, V., Stoks R., De Block M., \& Johansson F. (2012). Generalists and specialists along a latitudinal transect: patterns of thermal adaptation in six species of damselflies. Ecology, 93, 1340 - 1352. https://doi.org/10. $1890 / 11-1910.1$

Nilsson-Örtman, V., Stoks R., \& Johansson F. (2014). Competitive interactions modify the temperature dependence of damselfly growth rates. Ecology, 95, $1394-1406$. https://doi.org/10.1890/13 -0875.1

Norling, U. (1971). The life history and seasonal regulation of Aeshna viridis Eversm. in southern Sweden (Odonata). Entomologica Scandinavica, 2, 170 - 190. https://doi.org/10.1163/187631271X00 194

Norling, U. (1976). Seasonal regulation in Leucorrhinia dubia (Vander Linden) (Anisoptera: Libellulidae). Odonatologica, $5,245-263$.

Norling, U. (1984a). The life cycle and larval photoperiodic responses of Coenagrion hastulatum (Charpentier) in two climatically different areas (Zygoptera: Coenagrionidae). Odonatologica, 13, 429-449.

Norling, U. (1984b). Photoperiodic control of larval development in Leucorrhinia dubia (Vander Linden): a comparison between populations from northern and southern Sweden (Anisoptera: Libellulidae). Odonatologica, 13, $529-550$.

Norling, U. (1984c). Life history patterns in the northern expansion of dragonflies. Advances in Odonatology, 2, $127-156$.

Norling, U. (2018). Constant and shifting photoperiods as seasonal cues during larval development of the univoltine damselfly Lestes sponsa (Odonata: Lestidae). International Journal of Odonatology, 21, 151-163. https://doi. org/10.1080/13887890.2018.1462263

Nygren G. H., Bergström A., \& Nylin S. (2008). Latitudinal body size clines in the butterfly Polyommatus icarus are shaped by gene-environment interactions. Journal of Insect Science, 8, 47. https://doi.org/10.1673/031 008.4701

Nylin, S., Wickman, P.-O., \& Wiklund, C. (1989). Seasonal plasticity and development of the speckled wood butterfly Pararge aegeria (Satyrinae). Biological Journal of the Linnean Society, 38, 155 - 171. https://doi.org/10.1111/ j.1095-8312.1989.tb01571.x

Parr, M.J., (1970). The life histories of Ischnura elegans (Van der Linden) and Coenagrion puella (L.) (Odonata) in south Lancashire. Proceedings of the Royal Entomological Society of London (A), 45, 172 - 181. https://doi.org/ 10.1111/j.1365-3032.1970.tb00844.x

Paulson, D.R., \& Jenner, C. E. (1971). Populations structure in overwintering larval Odonata in North Carolina in relation to adult flight season. Ecology, 52, $96-107$. https://doi.org/10.2307/1934740

Pritchard, G. (1982). Life-history strategies in dragonflies and the colonization of North America by the genus Argia (Odonata; Coenagrionidae). Advances in Odonatology, 1, 227-241.

Pritchard, G., \& Leggott, M. (1987). Temperature, incubation rates and origins of dragonflies. Advances in Odonatology, 3, 121-126.

Pritchard, G., Harder, L. D., \& Mutch, R. A. (1996). Development of aquatic insect eggs in relation to temperature and strategies for dealing with different thermal environments. Biological Journal of the Linnean Society, 58, 221-244. https://doi.org/10.1111/j.1095-8312.1996.tb01432.x

Réale, D., Garant, D., Humphries, M. M., Bergeron, P., Careau, V., \& Montiglio, P.-O. (2010). Personality and the emergence of the pace-of-life syndrome concept at the population level. Philosophical Transactions of the Royal Society B: Biological Sciences, 365, 4051-4063. https://doi.org/10.1098/rstb.2010.0208

Richter, O., Suhling, F., Müller, O., \& Kern D. (2008). A model for predicting the emergence of dragonflies in a changing climate. Freshwater Biology, 53, 1868 - 1880, 1-13. https://doi.org/10.1111/j.1365-2427.2008.02012. $\mathrm{x}$

Robert, P.-A. (1959). Die Libellen. Bern: Kümmerley \& Frey. [authorized translation by O.P. Wenger; original edition: 1958, Les Libellules. Neuchatel: Delachaux \& Niestlé].

Roff, D. A. (1983). Phenological adaptation in a seasonal environment: a theoretical perspective. In V. K. Brown \& I. Hodek (Eds.), Diapause and life cycle strategies in insects, $253-370$. Series Entomologica. The Hague: Junk.

Rohr, J. R., Civitello, D. J., Cohen, J. M., Roznik, E. A., Sinervo, B., \& Dell I. (2018). The complex drivers of thermal acclimation and breadth in ectotherms. Ecology Letters, 21, 1425-1439. https://doi.org/10.1111/ele.13 107

Sackville, M., Brauner, C. J., \& Matthews, P. G. D. (2019). Complete larval development of the dragonfly, Rhionaeschna multicolor, at $20^{\circ} \mathrm{C}$ under natural photoperiod (Odonata: Aeshnidae). Notulae Odonatologicae, 9, 103 108.

Samraoui, B., \& Corbet, P. S. (2000). The Odonata of Numidia, northeastern Algeria. Part II. Seasonal ecology. International Journal of Odonatology, 3, 27-39. https://doi.org/10.1080/13887890.2000.9748 134

Saunders, D. S. (2014). Insect photoperiodism: effects of temperature on the induction of insect diapause and diverse roles for the circadian system in the photoperiodic response. Entomological Science, 17, 25-40. https://doi.org/ 10.1111/cns.12059

Sawchyn, W. W. (1971). Environmental controls in the seasonal succession and synchronization of development in some pond species of damselflies (Odonata: Zygoptera) (Unpublished doctoral dissertation). University of Saskatchewan, Saskatoon. Retrieved from https://harvest.usask.ca/handle/10388/etd-05272011-135954

Schaller, F. (1960). Étude du développement postembryonaire d'Aeshna cyanea Müll [Study of the postenbryonal development of Aeshna cyanea Müll]. Annales des Sciences Naturelles Zoologique et Biologique Animales, 2, $751-868$. 
Schaller, F., Andries, J. C., Mouze, M., \& Defossez, A. (1974). Nouveaux aspects du contrôle hormonal du cycle biologique des odonates: recherches sur la larve d'Aeshna cyanea (Müller) (Anisoptera: Aeshnidae) [New aspects of the hormonal control of odonate life cycles: research on the larva of Aeshna cyanea (Müller) (Anisoptera: Aeshnidae)]. Odonatologica, 3, $49-62$.

Seebacher, F., Brand, M. D., Else, P., Guderley, H., Hulbert, A. J., \& Moyes, C. D. (2010). Plasticity of oxidative metabolism in variable climates: molecular mechanisms. Physiological and Biochemical Zoology, 83, $721-732$. https://doi.org/10.1086/649964

Shama, L. N. S., Campero-Paz, M., Wegner, K. M., De Block, M., \& Stoks, R. (2011). Latitudinal and voltinism compensation shape thermal reaction norms for growth rate. Molecular Ecology, 20, 2929-2941. https://doi.org/ 10.1111/j.1365-294X.2011.05 156.X

Śniegula, S., Gołab, M. J., \& Johansson, F. (2017). Cannibalism and activity rate in larval damselflies increase along a latitudinal gradient as a consequence of time constraints. BMC Evolutionary Biology 17:167. https://doi.org/10. $1186 / \mathrm{s} 12862-017-1010-3$

Śniegula, S., Johansson, F., \& Nilsson-Örtman, V. (2012). Differentiation in developmental rate across geographic regions: a photoperiod driven latitude compensating mechanism? Oikos, 121, 1073-1082. https://doi.org/10. 1111/j.1600-0706.2011.20015.x

Śniegula, S., Nilsson-Örtman, V., \& Johansson, F. (2012). Growth pattern responses to photoperiod across latitudes in a northern damselfly. PLoS One, 7(9), e46024. https://doi.org/10.1371/journal.pone.0046024

Stoks, R., \& Córdoba-Aguilar, A. (2012). Evolutionary ecology of Odonata: A complex life cycle perspective. Annual Review of Entomology, 57, 249 - 265. https://doi.org/10.1146/annurev-ento-120710 - 100557

Stoks, R., \& de Block, M. (2011). Rapid growth reduces cold resistance: Evidence from latitudinal variation in growth rate, cold resistance and stress proteins. PLoS One, 6(2), e16935. https://doi.org/10.1371/journal.pone. 0016935

Stoks, R., Geerts, A. N., \& De Meester, L. (2013). Evolutionary and plastic responses of freshwater invertebrates to climate change: realized patterns and future potential. Evolutionary Applications, 7, 42-55. https://doi.org/10. 1111/eva.12 108

Stoks, R., Johansson, F., \& De Block, M. (2008). Life-history plasticity under time stress in damselfly larvae. In A. Cordoba-Aguilar (Ed.), Dragonflies: Model Organisms for Ecological and Evolutionary Research (pp. 39 - 51). Oxford: Oxford University Press. https://doi.org/10.1093/acprof:oso/9780199230693003.0004

Stoks, R., Swillen, I., \& De Block, M. (2012). Behaviour and physiology shape the growth accelerations associated with predation risk, high temperatures and southern latitudes in Ischnura damselfly larvae. Journal of Animal Ecology, 81, 1034 - 1040. https://doi.org/10.1111/j.1365-2656.2012.01987.x

Suhling, F., Sahlén, G., Gorb, S., Kalkman, V., Dijkstra, K-D., \& van Tol, J. (2015). Order Odonata. In J. Thorp \& D. C. Rogers (Eds.), , Ecology and general biology: Thorp \& Covich ś freshwater invertebrates, Volume 1 (pp. $893-$ 932). Academic Press. https://doi.org/10.1016/B978-0-12-385026-3.00 035-8

Suhling, F., Suhling I., \& Richter O. (2015). Temperature response of growth of larval dragonflies - an overview. International Journal of Odonatology, 18, 15-30. https://doi.org/10.1080/13887890.2015.1009392

Tauber, M. J., Tauber, C. A., \& Masaki, S. (1986). Seasonal adaptations of insects. Oxford: Oxford University Press.

Thompson, A. (2019). The life history of Anax junius (Drury) in Minnesota: Determining instars, growth development pathways, emergence phenology, and the effect of temperature on development (Odonata: Aeshnidae). (Unpublished doctoral dissertation). University of Minnesota, Minneapolis-Saint Paul. Retrieved from http://hdl.hand le.net/11299/211 809

Trottier R. (1971). Effect of temperature on the life-cycle of Anax junius (Odonata: Aeshnidae) in Canada. The Canadian Entomologist, 103, 1671-1683. https://doi.org/10.4039/Ent1031671-12

Tüzün, N., Op de Beeck, L., Bran, K. I., Janssens, L., \& Stoks, R. (2017). Microgeographic differentiation in thermal performance curves between rural and urban populations of an aquatic insect. Evolutionary Applications, 10, 1067- 1075. https://doi.org/10.1111/eva.12512

Tüzün, N., \& Stoks, R. (2018). Evolution of geographic variation in thermal performance curves in the face of climate change and implications for biotic interactions. Current Opinion in Insect Science, 29, 78 -84. https://doi. org/10.1016/j.cois.2018.07004

Ueda, T. (1978). Geographic variation in the life cycle of Lestes sponsa. Tombo, 21, 27-34.

Ueda, T. (1989). Sexual maturation, body colour changes and increase of body weight in a summer diapause population of the damselfly Lestes sponsa (Hansemann) (Zygoptera: Lestidae). Odonatologica, 18, 75 -87.

Van Dievel, M., Tüzün, N., \& Stoks, R. (2019). Latitude-associated evolution and drivers of thermal response curves in body stoichiometry. Journal of Animal Ecology, 88, 1961 - 1972. https://doi.org/10.1111/1365 - 2656.13088

Van Doorslaer, W., \& Stoks, R. (2005a). Thermal reaction norms in two Coenagrion damselfly species: Contrasting embryonic and larval life-history traits. Freshwater Biology, 50, 1982-1990. https://doi.org/10.1111/j.13652427.2005.01443.x

Van Doorslaer, W., \& Stoks, R. (2005b). Growth rate plasticity to temperature in two damselfly species differing in latitude: Contributions of behaviour and physiology. Oikos, 111, 599-605. https://doi.org/10.1111/j.1600-0706. 2005.14335.x

Verheyen, J., \& Stoks, R. (2019a). Temperature variation makes an ectoterm more sensitive to global warming unless thermal evolution occurs. Journal of Animal Ecology, 88, 624 - 636. https://doi.org/10.1111/1365 - 2656.12946 
Verheyen, J. \& Stoks, R. (2019b). Current and future daily temperature fluctuations make a pesticide more toxic: Contrasting effects on life history and physiology. Environmental Pollution, 248, 209-218. https://doi.org/10. 1016/j.envpol.2019.02022

Verheyen, J., Temmerman, K., De Block, M., \& Stoks, R. (2018). Voltinism-associated differences in winter survival across latitudes: integrating growth, physiology, and food intake. Oecologia, 186, 919-929. https://doi.org/10. 1007/s00 442-018-4079-5

Verheyen, J., Tüzün, N., \& Stoks, R. (2019). Using natural laboratories to study evolution to global warming: contrasting altitudinal, latitudinal, and urbanization gradients. Current Opinion in Insect Science, 35, 10 - 19. https:// doi.org/10.1016/j.cois.2019.06001

Visser, M. E., Caro, S. P., van Oers, K., Schaper, S. V., \& Helm, B. (2010). Phenology, seasonal timing and circannual rhythms: towards a unified framework. Philosophical Transactions of the Royal Society, B, 365, 3113-3127. https://doi.org/10.1098/rstb.2010.0111

Waringer, J. (1982). Der Einfluss der Wassertemperatur auf die Dauer der Embryonal- und Larvalentwicklung von Coenagrion puella $L$. aus einem Tümpel bei Herzogenburg (N. Ö.). [The influence of water temperature on the duration of embryonic and larval development of Coenagrion puella L. from a pond at Herzogenburg (N. Ö.)]. (Unpublished doctoral dissertation). University of Vienna, Austria.

Waringer, J. A., \& Humpesch, U. H. (1984). Embryonic development, larval growth and life cycle of Coenagrion puella (Odonata: Zygoptera) from an Austrian pond. Freshwater Biology, 14, 385-399. https://doi.org/10.1111/j. 1365 - 2427.1984.tb00 162.x

Zaslavsky, V.A. (1972). Two-stage photoperiodic reactions as a starting point for the production of a model of the photoperiodic control of arthropod development [in Russian]. Entomologicheskoe Obozrenie, 51, 217-239. Translated in Entomological Review, 51, 133 - 145. 